\title{
ROOF SLOPE EFFECTS ON THE AERODYNAMIC CHARACTERISTICS OF TALL BUILDINGS
}

\author{
Iddir Boumrar $^{1 *}$ - Abdelhamid Becheur ${ }^{2}$
}

\author{
${ }^{1}$ Département de Génie Mécanique, Université Mouloud Mammeri de Tizi-Ouzou, 15000, Algérie. \\ Laboratoire d'Energétique Mécanique et Matériaux, LEMM \\ ${ }^{2}$ Département de Génie Mécanique, Université Abderrahmane Mira de Bejaia, 06000, Algérie. \\ Laboratoire de Recherche en Hydraulique Appliquée et Environnement, LRHAE
}

\begin{tabular}{l} 
ARTICLE INFO \\
\hline Article history: \\
Received 18.6.2019. \\
Received in revised form 8.2.2020. \\
Accepted 8.2.2020. \\
\hline Keywords: \\
Bluff-body aerodynamics \\
Wind force \\
Wind pressure distribution \\
Tall buildings \\
CFD simulation \\
Building roof shape \\
\hline DOI: https://doi.org/10.30765/er.1481
\end{tabular}

\section{Introduction}

The flow generated by a presence of a tall building, in wind boundary layer, is a configuration meets in many applications: aerodynamics and effects of wind around tall buildings, knowledge of pressures due to the flow on buildings faces and measurement of wind loads acting on the buildings windward side. Particularly the wind flow around rectangular, cubic or tapered tall buildings forms is a subject of many experimental and numerical studies:

The flow pattern in the building wake is illustrated with some swirl structures [1]; a pair of vertical vortices is induced by horseshoe vortex through the shear layers on the side walls and a relatively uniform pressure distribution has been observed in region close to the vertical sides of the leeward face. The flow is driven by a shear layer over the roof, the building wake is also found highly turbulent. Five rectangular building models having same plan area and same height but with different side ratios were tested in a wind tunnel [2]. It is deduced that wind pressure evolutions on the leeward and sidewalls faces, are dependent of building side ratio.

\footnotetext{
${ }^{*}$ Corresponding author

E-mail address: boumrari@hotmail.fr

\begin{abstract}
Roof shape of a building placed in a wind flow has particularly ificant effects on this flow, in its wake, immediately at the experimental study, undertaken on rectangular models of reduced scale skyscrapers $(1: 1000)$, in a subsonic wind tunnel that enabled uneasure the exerted force by wind flow on windward face of longitudinal and the transverse building directions. The drag force acting on the models windward face is very affected by the building soof; these results are available for a normal and inclined complex flow developed around the different building models, using Fluent software. We obtain the parietal pressure distribution on the various building faces and we compare the numerical values to the experimental data obtained inthe wind tunnel, both are in good agreement with those provided by the international ASCE code. The numerical simulation indicates that complex structure
vortices are developed at the buildings wake and allows us a better understanding of the flow phenomena. Analysis of the numerical results reveals a distinct evolution of pressure and velocity fields, the induced downstream flow is particularly complex. The
presence of a roof deforms swirling zones: the zone of recirculation in buildings wake is stretched and the flow diagram is modified, which has direct effects on the measured wind force and the pressure distribution.
\end{abstract}


Wind pressure acting on windward wall is not affected by the side ratio. The building mean displacements and its torque are seriously affected by wind incidence angles and side ratio values. A study focused on helical models with triangular cross-sections [3] is presented to identify the effects of helical cross-sections on pressure distribution of and force coefficients. Models with helical angles of $60^{\circ}, 180^{\circ}$, and $360^{\circ}$ with equilateral triangle sectional shape were used, all having the same volume; maximum and minimum of wind force coefficients are deduced at all the wind directions for different helical models. Random decrement technique was applied to study 15 aeroelastic models of rectangular super-high-rise buildings [4]. The aerodynamic damping ratio is affected by turbulence intensity, buildings side ratio and less by aspect ratio. Empirical aerodynamic damping functions are deduced to estimate aerodynamic damping ratios at different reduced speeds for rectangular buildings with an aspect ratio in the range of 5 to 10 , a side ratio of $1 / 3$ to 3 , and turbulent intensity varying from $1.7 \%$ to $25 \%$.

Tall buildings are particularly exposed to natural disasters like strong winds and earthquakes. One way to minimize wind-induced vibrations of tall buildings is to focus more on their shapes in the design stage. Particularly, the variations in along-wind and crosswind overturning moment coefficients, power spectral densities, and trajectories of various wind force coefficients which were widely studied [5]. Some experimental results of wind pressure distributions, aerodynamic force coefficients, and Strouhal numbers were presented for 12 models of rectangular prisms with various side ratios and rounded corners, at different Reynolds numbers [6]. Obtained results show that the sensitivity of aerodynamic behavior to the Reynolds number increases with increasing side ratio or rounded corner ratio for rectangular prisms.

An overview [7] of the factors influencing accurate prediction of dynamic properties response using wind tunnel testing, this response indeed correlates with observations. Wide ranging subjects are addressed in a manner that demonstrates the importance of continued promotion and expansion of full-scale monitoring efforts and the ways in which these programs can provide true value-added to building owners and managers. An experimental investigation [8] was undertaken in order to determine aerodynamic forces and wind pressures acting on square-plan tall building models with various configurations: corner cut, setbacks and helical. These experiments have led to understanding the aerodynamic characteristics of tall buildings with various configurations. The wind-induced displacement and acceleration responses, for three-tower connected tall building, in horizontal and torsional directions were investigated [9], subsequently the structural basal and floor under different return periods, wind directions and damping ratios are studied. Finally, the action mechanism of interference effect on structural wind effects is investigated. Conclusions provide a scientific basis for wind-resistant design of such three-tower connected tall building. Three symmetric, rectangular, tall building models on a typical open terrain were studied in a wind tunnel [10]. Time histories of wind pressure on these models under different reduced wind speeds and torsional amplitudes are obtained through the multiple point synchronous scanning pressure technique. The characteristics of both Root Mean Square (RMS) coefficients and spectra of the base shear/torque in along-wind, across-wind, and torsional directions, respectively, were discussed. It is identified that torsional vibration amplitudes and reduced wind speeds are two significant parameters for aerodynamic forces acting on the structures in the three directions.

Some tapered super high-rise buildings with a square cross section were tested in a wind tunnel by applying synchronous pressure measurement technology [11]. It is observed that the tapered elevation reduced vortex shedding energy and increase vortex shedding frequency. Chamfered modification eliminates across-wind vortex shedding and reduced residual energy. Opening a ventilation slot in the corner of equipment and refuge floors further suppressed the vortex shedding strength. A numerical analysis was undertaken at a wind incidence angle equal to $0^{\circ}$ [12], pressure evolution on different faces of octagonal plan shaped tall building and three identical square plans were obtained, the results were compared to the isolated condition. The interference factors (IF) evolutions were presented and we observe an abnormal and not predictable pressure distribution due to the presence of the interfering buildings. The pressure coefficient $(\mathrm{Cp})$ on each face of the octagonal plan shaped building in each interfering case is found if we multiply the IF with the $\mathrm{Cp}$ in the isolated case. In order to validate different turbulence models for predicting airflow patterns, three types of common agricultural buildings, arched-type, pitched-type and flat-type roof, were examined by conducting experiments in a wind tunnel with controlled airflow conditions [13], the focus was the description of the external airflow field in the wake of each building. A reasonable agreement was found between experimental and simulation results. Pressure distribution around enclosed and open-window high-rise buildings was studied, using wind tunnel model tests and numerical analyses [14]. This study shows that the wind pressure coefficient increases 
slightly after opening the windows of the buildings. The wind pressure coefficient is independent of the wind velocity of inflow. Furthermore, different incident angles of wind were considered.

The principal goal of these above studies is to analyze the physical phenomena, at the origin of these flows and to study the influence of the flow parameters characteristics. However, majority of the wind effect studies on tall buildings are carried out in order to better understand the flow topology around a given geometry. The roof influence is relatively less studied comparing to the other parameters (Reynolds number, blocking rate, depth, height...). Thus, to constitute a data bank of pressure field on the walls of geometries placed in a wind.

In the present paper, we undertook an aerodynamic study of four building-models, in a subsonic wind tunnel in order to understand the evolution of the three-dimensional flow. The pressure distribution at different faces of the four studied configurations (with and without roof), make it possible to introduce the importance of the roof shape on the formation of swirls zones in the building wake and other directions. The principal objective of our work is the description of the building roof shape influence on the flow upstream and especially downstream, by measuring the aerodynamic pressure coefficient $\mathrm{Cp}$ and the wind flow load acting on the windward face called the drag D. The roof with inclined sloops is stuck centrally at the building top. Numerical simulation is carried out using Fluent software code of "Computational Fluid Dynamics" [15], which gives us an idea on the phenomenological aspects developing around building models. The principal objective sought is the design of buildings with optimized aerodynamic form in connection with the structures resistance.

\section{Experimental setup}

\subsection{Wind tunnel}

The experiments were undertaken in a subsonic wind tunnel shown in Figure 1. The wind tunnel test section has $300 \mathrm{~mm}$ (height), $300 \mathrm{~mm}$ (width) and $1000 \mathrm{~mm}$ (length); it is composed by plate walls of Altuglas provided with several holes allowed to introduce the studied models and some measuring instruments.

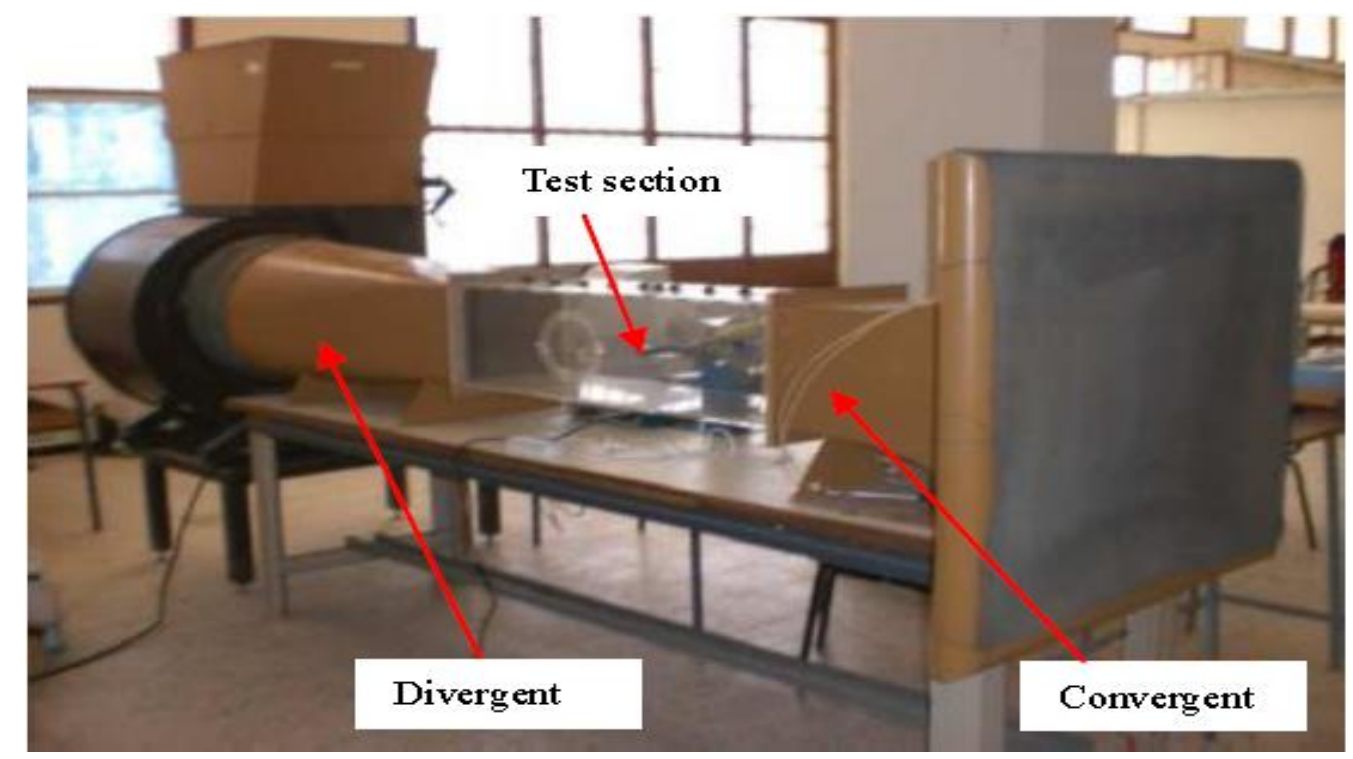

Figure 1. Photography of the used wind tunnel.

The wind tunnel is supplemented by the following measurement means:

A multi-manometer, composed by 24 tubes, allows measurements of pressure by reading oil heights prevailing in the multi-manometer tubes. The pressure coefficient $\mathrm{Cp}$ is given by the following relation:

$$
\mathrm{Cp}=\frac{\mathrm{P}-\mathrm{P}_{\mathrm{o}}}{\frac{1}{2} \rho \mathrm{V}_{\mathrm{o}}^{2}}
$$


A double Pitot tube, connected to the multi-manometer, for measuring the wind flow velocity Vo in the test section varying in range 0 to $45 \mathrm{~m} / \mathrm{s}$, Vo is given by the Bernoulli relation:

$$
\mathrm{V}_{\mathrm{o}}=\sqrt{\frac{2 \rho_{\mathrm{H}} \mathrm{g} \cdot \Delta \mathrm{h}}{\rho}}
$$

An aerodynamic balance provided with strain gauges, connected to a data acquisition chain, allows us to determine the aerodynamic force, exerted on windward face of the building model (the drag D).

Esam 1000 software allows us to regulate the suitable parameters for each measure: time between two successive measurements and the frequency of acquisition. For each model configuration we carried out several independent tests.

\subsection{Studied models}

Four geometries, placed in a three-dimensional wind flow, were retained in order to study aerodynamically effects of roof shape on downstream flow: 4 building models with a height of $200 \mathrm{~mm}$ and inclined roof slopes with the following angles $\theta=0,25,30$ and $33^{\circ}$ are tested in the wind tunnel (Figure 2 and Table. 1).

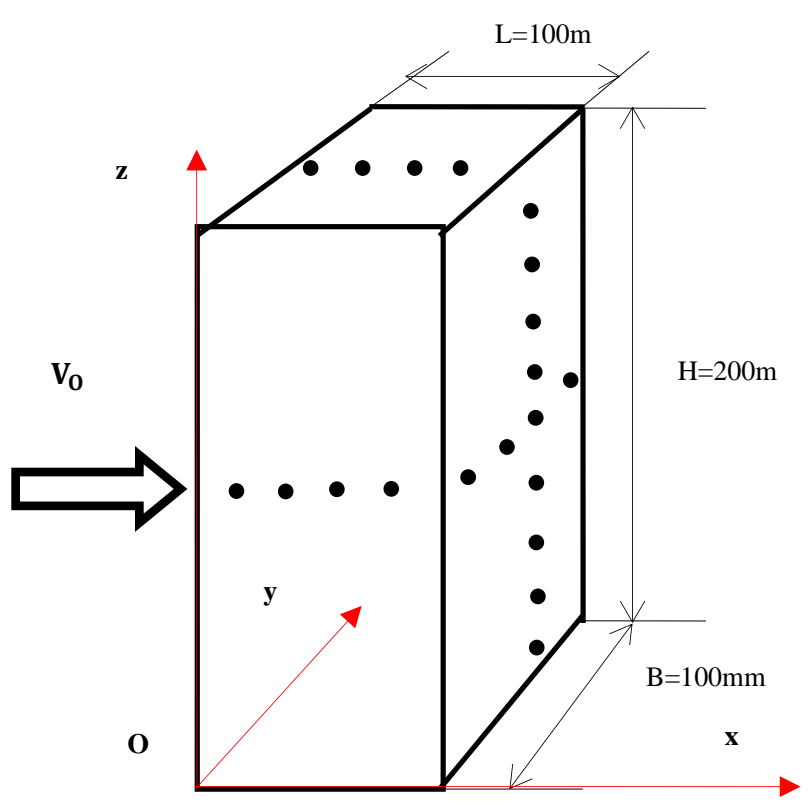

(a) Building with flat $\operatorname{roof} \theta=0^{\circ}$

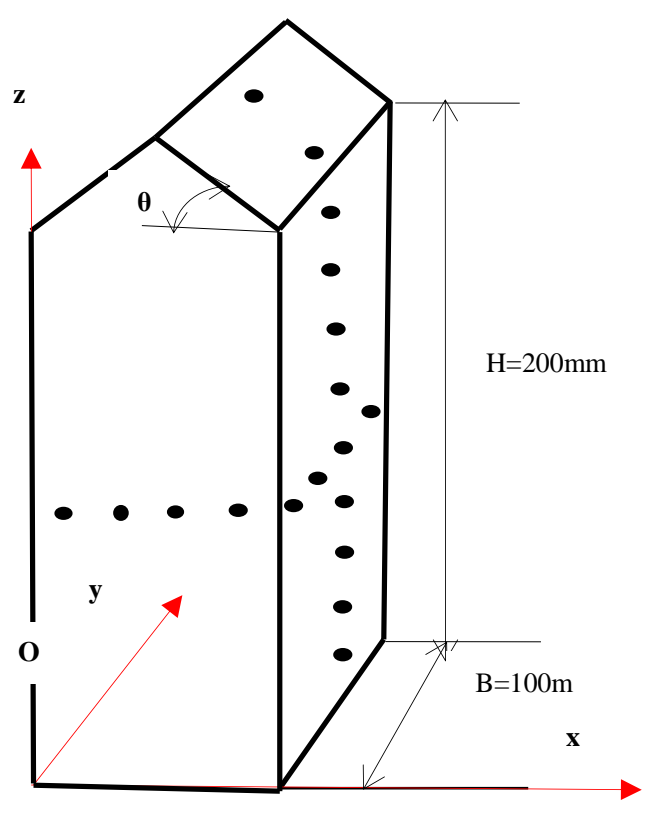

(b) Buildings with tilted slopes roof, the angle of inclination $\theta \neq 0^{\circ}$

Figure 2. Studied models (with reduced scale 1:1000).

Table 1. Geometrical characteristic of studied building models.

\begin{tabular}{ccccc}
\hline $\begin{array}{c}\text { Studied building } \\
\text { models }\end{array}$ & $\begin{array}{c}\text { Height } \\
\mathrm{H}(\mathrm{mm})\end{array}$ & $\begin{array}{c}\text { Width } \\
\mathrm{B}(\mathrm{mm})\end{array}$ & $\begin{array}{c}\text { Depth } \\
\mathrm{L}(\mathrm{mm})\end{array}$ & $\begin{array}{c}\text { Roof angle slope } \\
\theta\left({ }^{\circ}\right)\end{array}$ \\
\hline Model $\mathrm{n}^{\circ} 1$ & 200 & 100 & 100 & 0 \\
\hline Model $^{\circ} 2$ & 200 & 100 & 100 & 25 \\
\hline Model $\mathrm{n}^{\circ} 3$ & 200 & 100 & 100 & 30 \\
\hline Model $\mathrm{n}^{\circ} 4$ & 200 & 100 & 100 & 33 \\
\hline
\end{tabular}

The building models realized are provided at each given position $(\mathrm{x}, \mathrm{y}, \mathrm{z})$, with several pressure taps distributed on the various building faces. A suitable support allows the fixation of the model in the wind tunnel test section. 
All the pressure taps on studied model are connected to the multi-manometer (with oil columns), who allow us to read the various heights of oil photographed with a numerical apparatus, thereafter we calculate the pressure coefficient $\mathrm{Cp}$, corresponding to each pressure tap, using the relation given by Eq. (1).

The first series of pressure taps was distributed according to the longitudinal model plan as follow: 9 pressure taps at the windward face, 4 pressure taps on the roof and 9 pressure taps at the leeward face of the building; the second series of pressure taps was in the transverse direction where we have 4 pressure taps on the windward face, 4 on the leeward face and 4 pressure taps on each wall side (on right and lift walls of the building), this allows us to take measurements on all faces and directions of studied geometries, simultaneously in the wake flow and at the vicinity of all the walls (upstream, on the roof, downstream and on the two wall sides of each model building).

\section{Experimental results}

The experimental results are presented in terms of wind force acting on the building windward face and pressure distribution prevailing at different faces windward, leeward, roof and sidewalls.

\subsection{Wind force acting on buildings windward face (Drag)}

According to the four curves of Figure 3, we note that for all considered wind velocities, we have always the force which acts on model $n^{\circ} 3$ (roof inclined with angle $\theta=30^{\circ}$ ) relatively less significant compared to forces obtained on other studied models; this is valid for all the wind directions $\left(\beta=45^{\circ}\right.$ and $\left.\beta=90^{\circ}\right)$.

Drag force increases with wind flow velocity for model $\mathrm{n}^{\circ} 1$, but for the three other models we see that after $\mathrm{V}_{\mathrm{o}}=20 \mathrm{~m} / \mathrm{s}$ drag force tends to a same value $\mathrm{D}=12 \mathrm{~N}$ for a normal wind direction $\left(\beta=90^{\circ}\right)$, and $\mathrm{D}=10 \mathrm{~N}$ for inclined wind direction with an angle $\beta=45^{\circ}$.

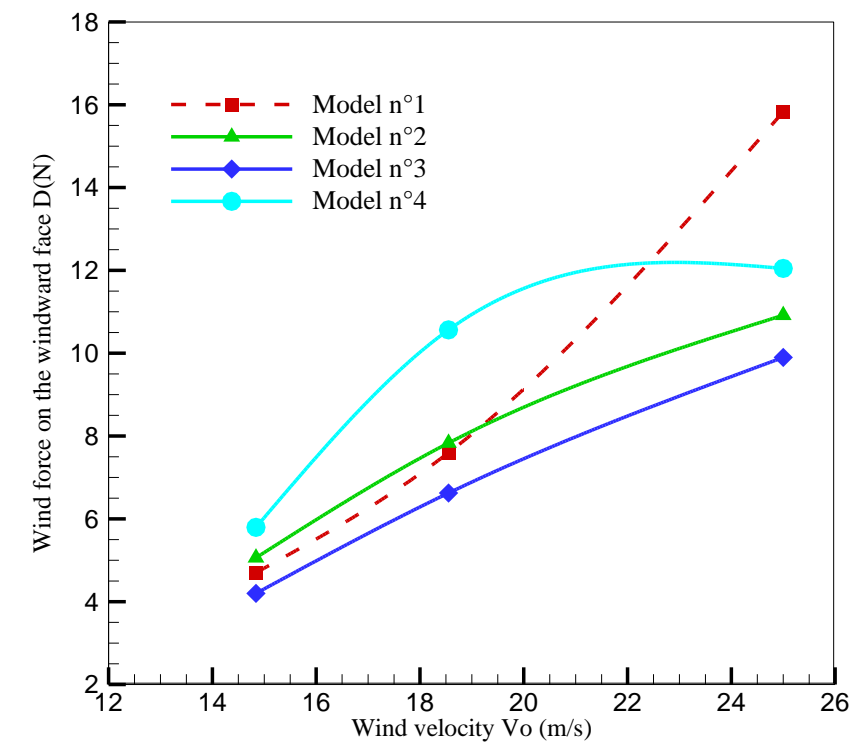

(a) Wind flow direction $\beta=90^{\circ}$

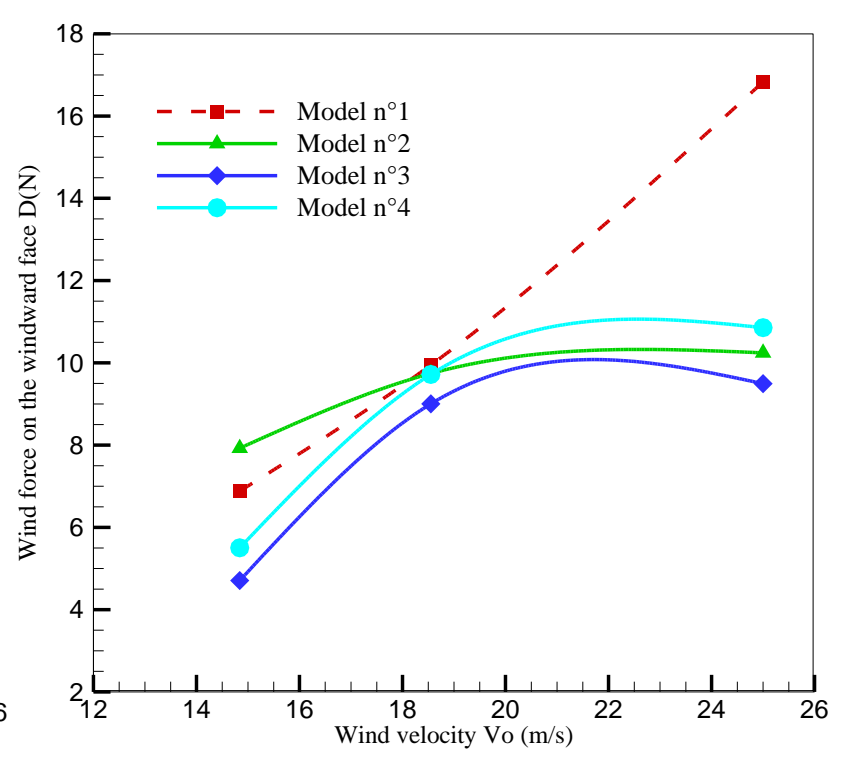

(b) Wind flow direction $\beta=45^{\circ}$

Figure 3. Velocity effects on the wind force acting on windward face of studied models.

\subsection{Wind pressure distribution}

In the present paragraph we follow the pressure evolution on different building faces in order to show the roof slope effects.

\subsubsection{Pressure on buildings windward face}

Figure 4 bellow shows mean pressure distribution due to a flow pattern, generated by the presence of a building subjected at a normal wind, on the windward face, at which we are interested in the present paragraph. 


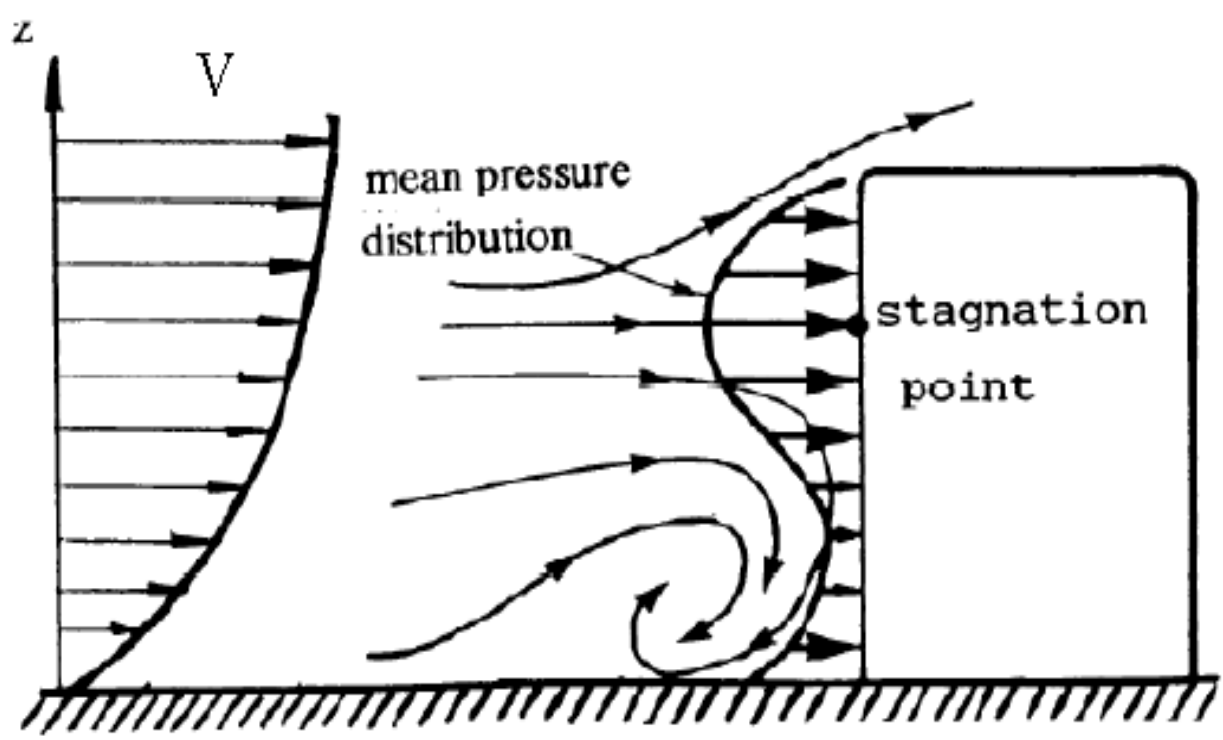

Figure 4. Wind flow diagram on building windward face [1].

Figure 5 shows evolution of defect pressure coefficient -Cp on windward face, it is almost the same for the four studied models; the wind flow is normal to the windward models face $\beta=90^{\circ}$. Concerning the two used velocities, the pressure evolution on windward face of model $n^{\circ} 1$ is almost constant, and the pressure evolution on windward faces of the three other models with inclined roof, behave same manner. We have a particular $\mathrm{Cp}$ evolution at the position $\frac{Z}{H}=0.70$ this is mentioned at [8].

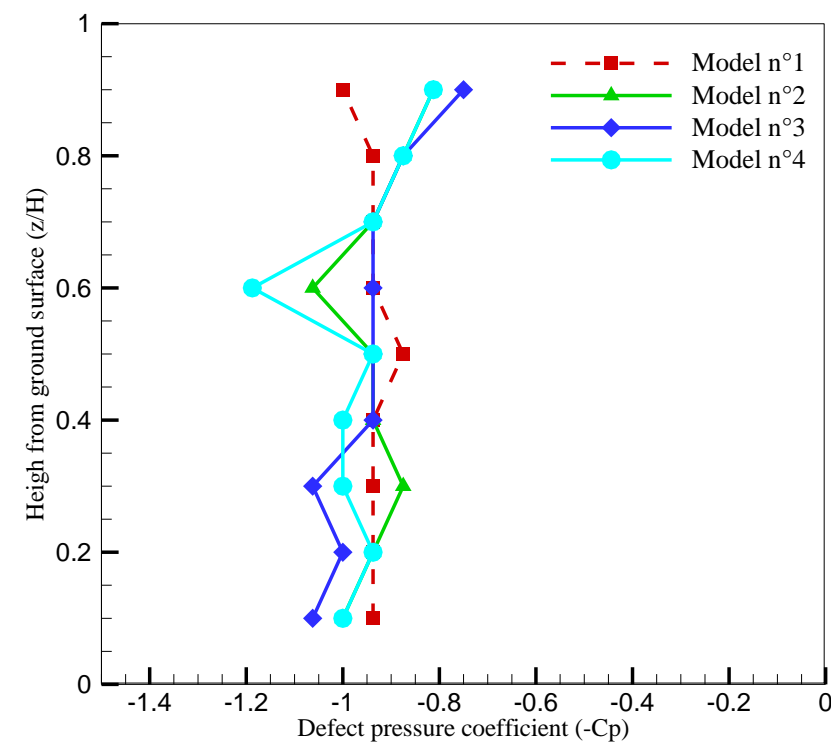

(a) Wind velocity $\mathrm{Vo}=15 \mathrm{~m} / \mathrm{s}$

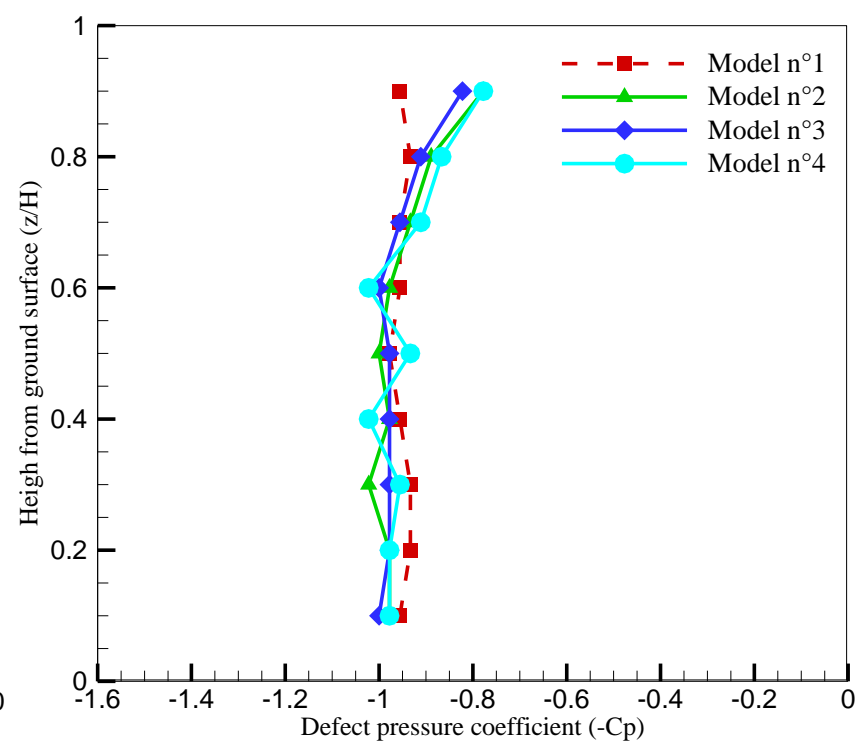

(b) Wind velocity $V_{0}=25 \mathrm{~m} / \mathrm{s}$

Figure 5. Defect pressure coefficient-Cp evolution on windward face of the studied models.

\subsubsection{Pressure on building's roof}

According to Figure 7, we notice that the majority of the points of the model with flat roof are at $-\mathrm{Cp}<0$, whereas various pressure taps of the other models are in depression and this depression increases with angle of inclination $\theta$ of the two roof slopes, these remarks are valid for the two considered velocities. Effects of roof shape are apparent, and we deduce that value of -Cp increases with $\theta$. 

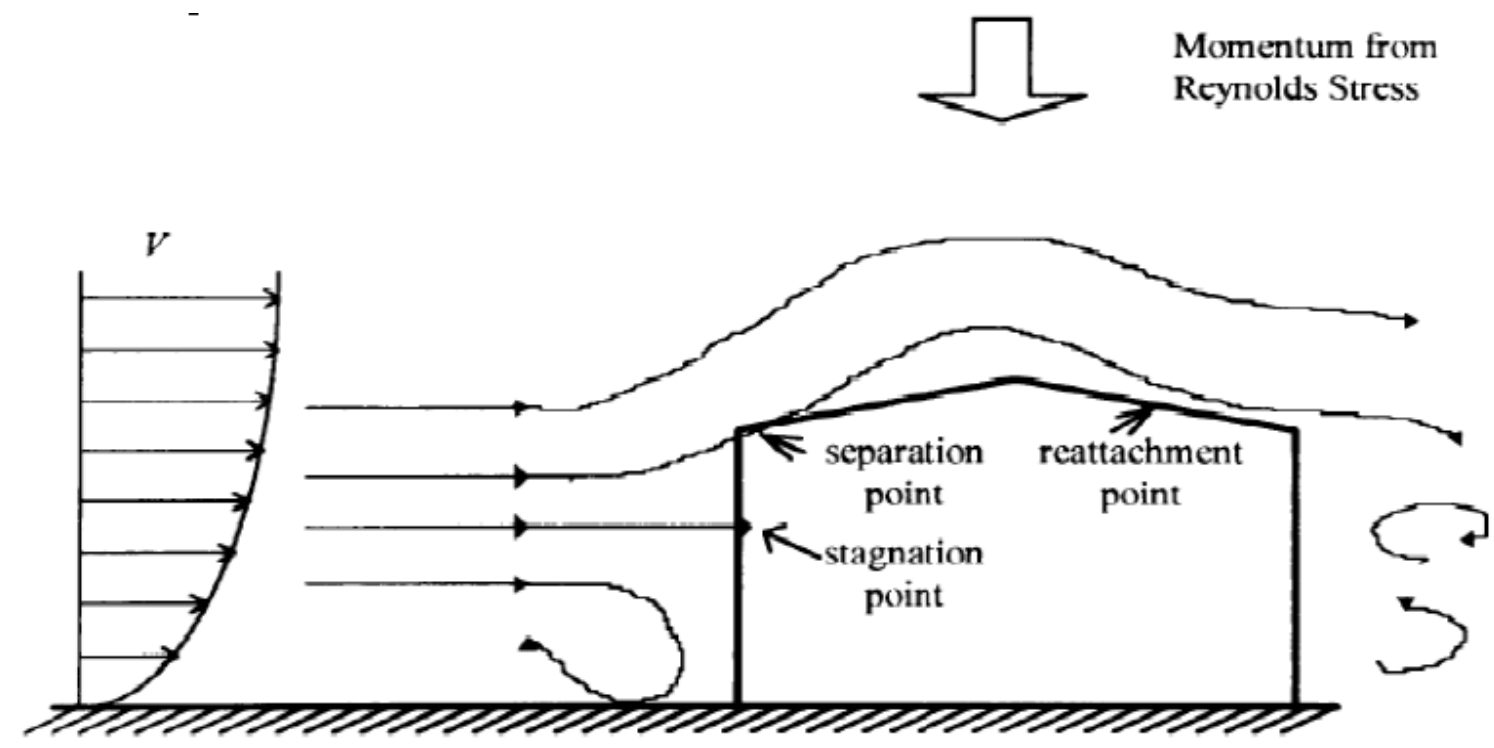

Figure 6. Cook results [1].

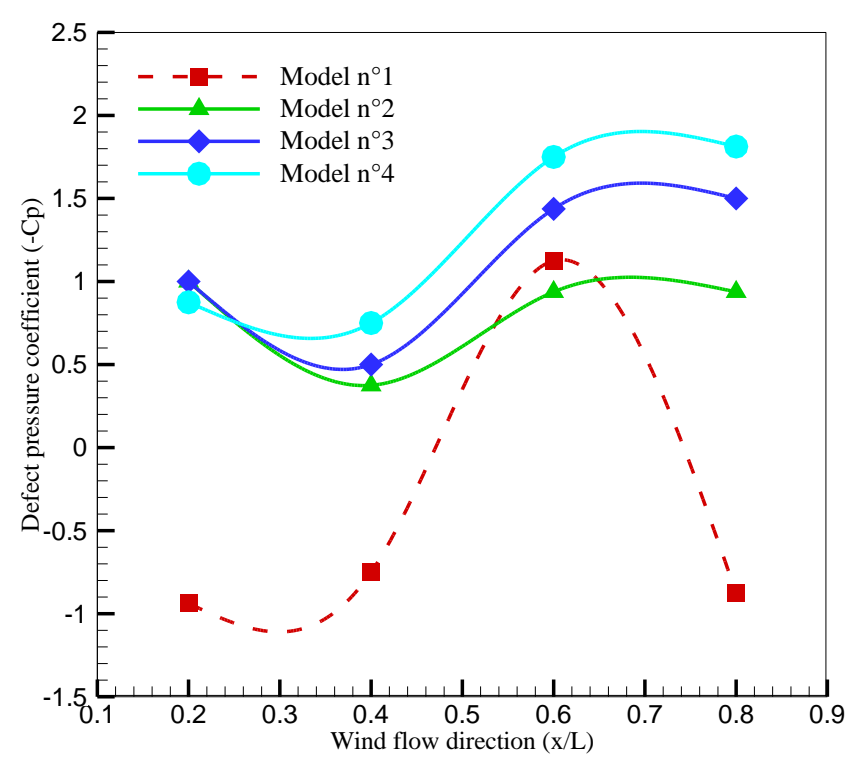

(a) Wind velocity $\mathrm{Vo}_{\mathrm{O}}=15 \mathrm{~m} / \mathrm{s}$

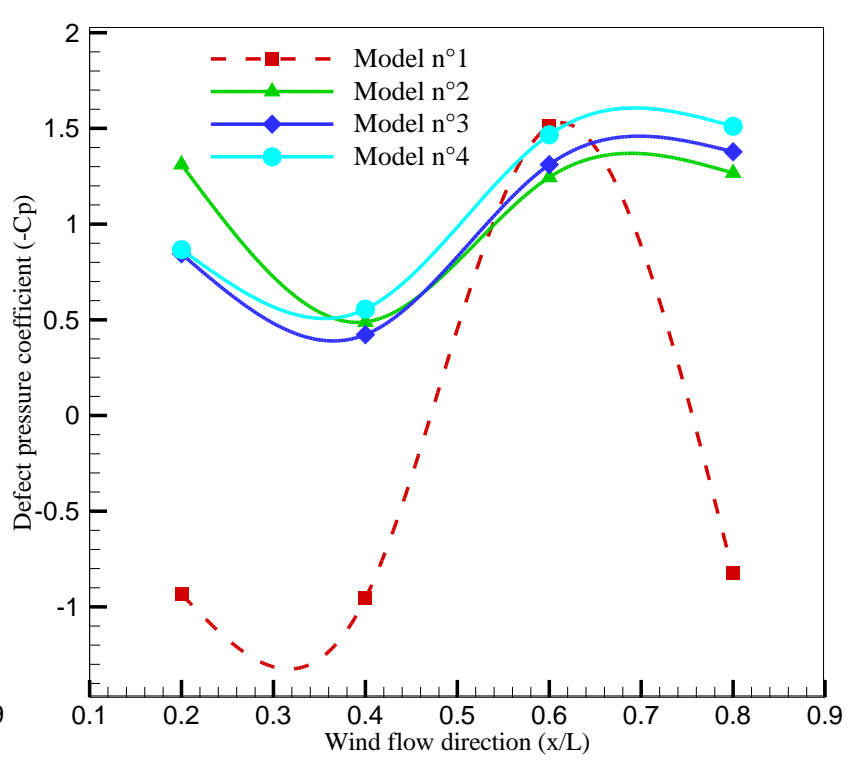

(b) Wind velocity $V_{0}=25 \mathrm{~m} / \mathrm{s}$

Figure 7. Defect pressure coefficient (-Cp) evolution on studied models roof.

\subsubsection{Pressure on buildings leeward face}

Figure 8 shows that for leeward face, and for the two models $\mathrm{n}^{\circ} 1$ and $\mathrm{n}^{\circ} 2$, for $\mathrm{z} \leq 0.10 \mathrm{H}$ at the vicinity of the buildings base where we have:

- $\mathrm{Cp}=0.7$, and for heights $0.10 \mathrm{H} \leq \mathrm{z} \leq 0.50 \mathrm{H}$ the defect pressure coefficient $-\mathrm{Cp}=-1$, and for $0.50 \mathrm{H} \leq \mathrm{z}$ the two curves are separated and we have $-\mathrm{Cp}=-1$ for the model $\mathrm{n}^{\circ} 1$ and $-\mathrm{Cp}=+1$ for the model $n^{\circ} 2$.

Then we conclude that:

- For model $\mathrm{n}^{\circ} 1$ (with flat roof), values of -Cp decrease until - $\mathrm{Cp}=-1$ at building heights $\frac{\mathrm{z}}{\mathrm{H}}<0.50$,

- For model $\mathrm{n}^{\circ} 2$, we have the same evolution of $-\mathrm{Cp}$ as model $\mathrm{n}^{\circ} 1$, except after the middle height $\left(\frac{\mathrm{z}}{\mathrm{H}} \geq 0.50\right)$, leeward face is at a constant depression $-\mathrm{C} \mathrm{p}=1$. 
- It is noted that according to this leeward face (Figure 8), depression behaves same manner for the two other models $n^{\circ} 3$ and $n^{\circ} 4$; more the roof slope is significant more measured value -Cp is important for the two considered velocities.

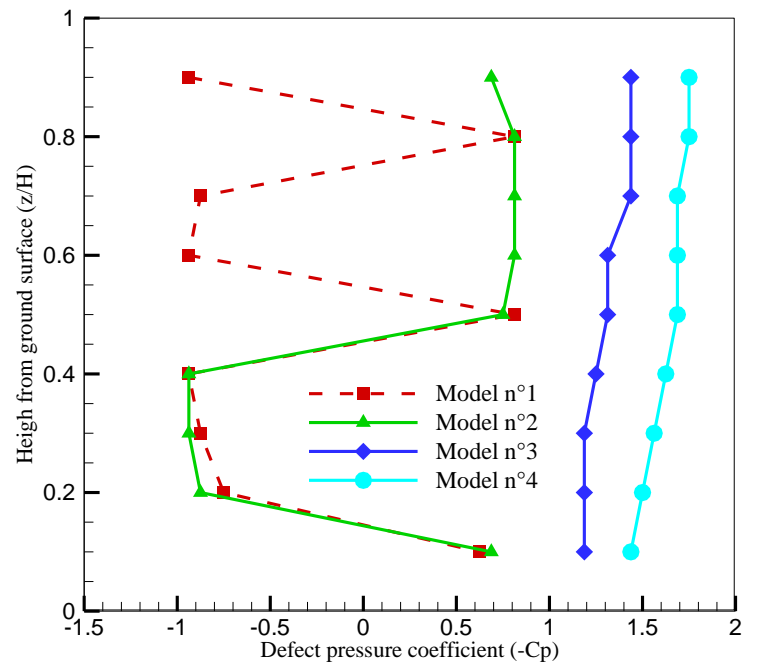

(a) Wind velocity $V_{0}=15 \mathrm{~m} / \mathrm{s}$

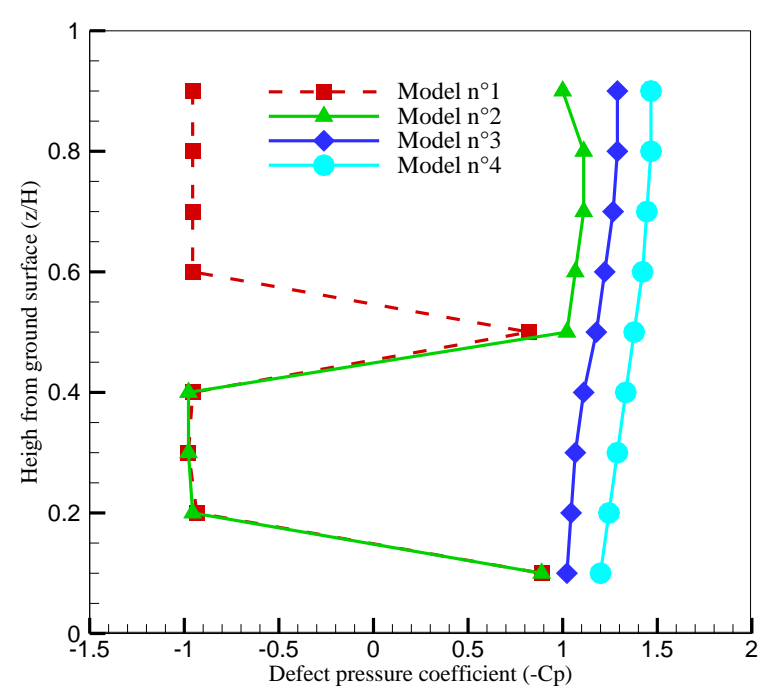

(b) Wind velocity $\mathrm{Vo}_{\mathrm{o}}=25 \mathrm{~m} / \mathrm{s}$

Figure 8. Defect pressure coefficient (-Cp) evolution on leeward face of studied models.

We conclude that at leeward face, value and evolution of -Cp with building height $\left(\frac{\mathrm{z}}{\mathrm{H}}\right)$ are affected by the roof shape and its slope inclination; furthermore the depression at the building wake increases with roof inclination angle $\theta$.

\subsubsection{Pressure on buildings side faces}

According to curves of Figure 9 and Figure 10, we notice that the evolution of defect pressure coefficient $-\mathrm{Cp}$, along longitudinal axis $\mathrm{Ox}$, is very affected by the building roof shape.

The majority of pressure taps on the right and left sides are at $-\mathrm{Cp}<0$, for the case of building with flat roof (model $n^{\circ} 1$ ). For other buildings with roof tilted slopes the defect pressure coefficient $-\mathrm{Cp}$ increases with angle $\theta$, this remark is applicable for the two considered velocities $\mathrm{Vo}=15$ and $25 \mathrm{~m} / \mathrm{s}$.

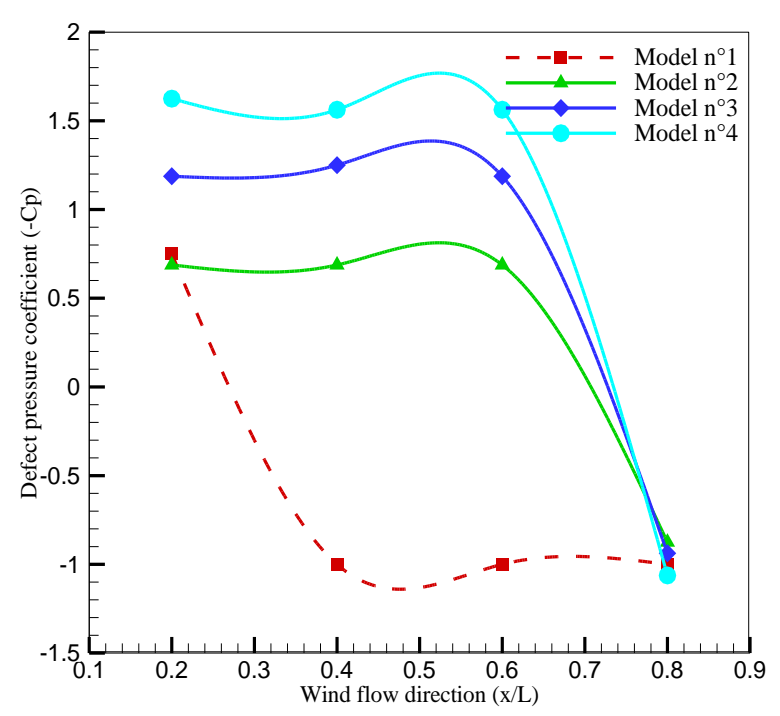

(a) Right side face

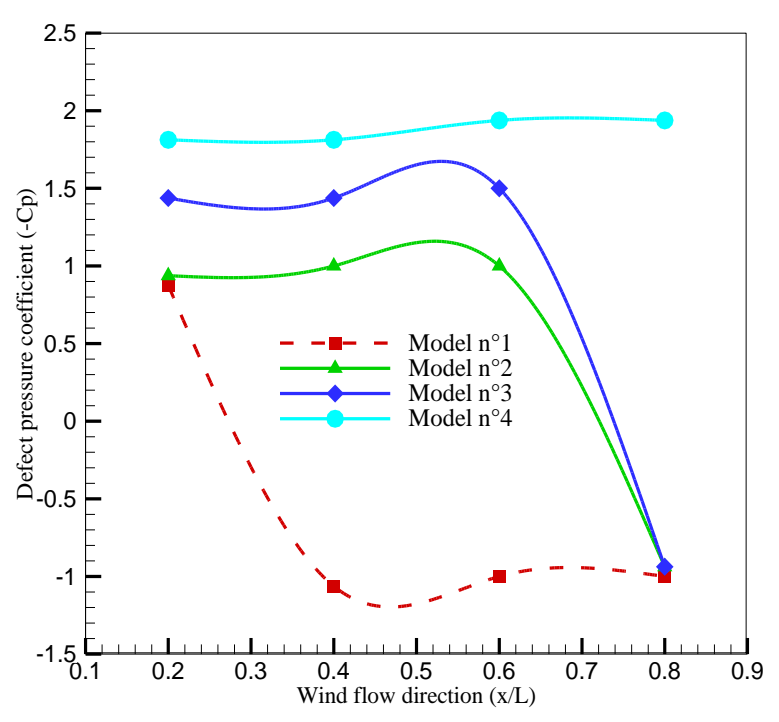

(b) Left side face

Figure 9. Longitudinal evolution of -Cp on the two side faces of studied models at Vo=15m/s. 


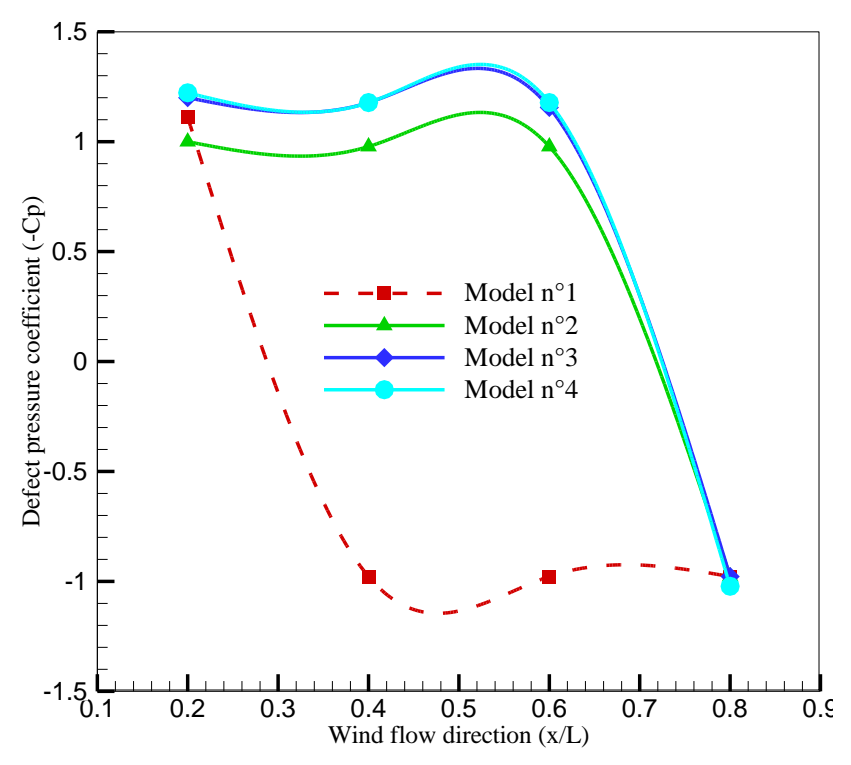

(a) Right side face

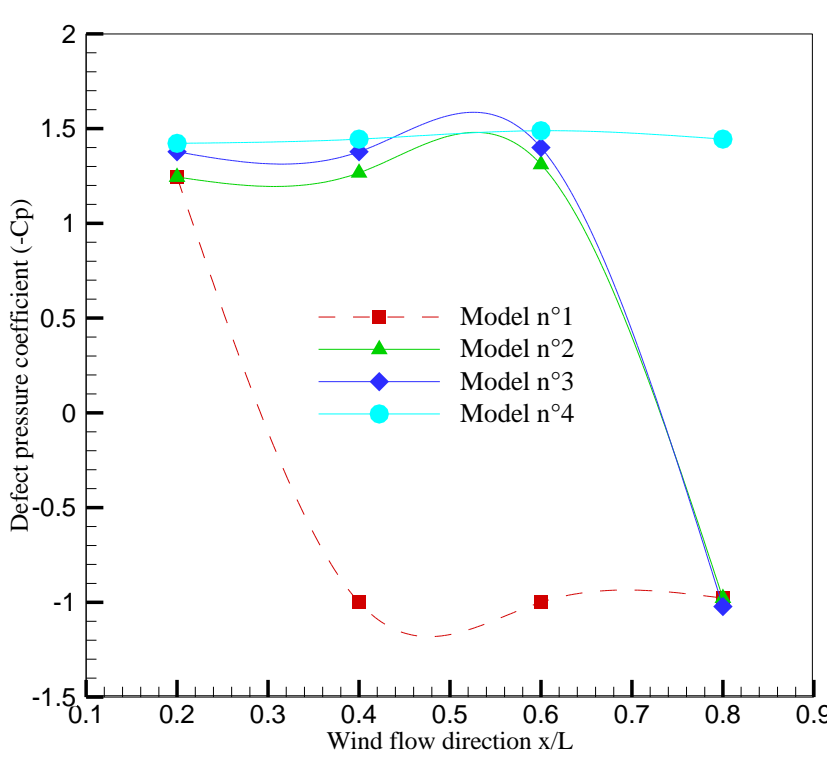

(b) Left side face

Figure 10. Longitudinal evolution of -Cp on the two side faces of studied models at Vo=25m/s.

It is noticed that for the particular position $\mathrm{x} / \mathrm{L}=0.8$, all the curves tend towards the same value $-\mathrm{Cp}=-1$ at the vicinity of the trailing edge of different models.

\section{Numerical simulation}

We considered a cube of fluid equivalent to the wind tunnel test section, its width $300 \mathrm{~mm}$, height $300 \mathrm{~mm}$ and depth $400 \mathrm{~mm}$. In the center is placed a building model-scale at a normal incidence to the wind flow $\beta=90^{\circ}$. The flow is reported to a reference frame, where $\mathrm{Oz}$ axis is vertical and perpendicular to the building base, $\mathrm{Ox}$ axis is positive in the flow direction and Oy axis is perpendicular to the plan Oxz. Air is the working fluid in the entire chosen cube with following properties: $\rho=1.22 \mathrm{~kg} / \mathrm{m}^{3}, v=1.510^{-5} \mathrm{~m}^{2} / \mathrm{s}$.

\subsection{Governing equations}

The wind flow in CFD simulation has been considered as turbulent and steady, but incompressible viscous fluid, which is characterized by Navier Stokes equations, as presented in the literature. It is suggested that realizable $k-\varepsilon$ turbulence model is sensitive to rapid strain and streamline curvature, flow separation, reattachment and recirculation.

In this paper, therefore, $k-\varepsilon$ turbulence model was employed to perform numerical simulation. The governing equations are presented as below:

Continuity:

$$
\frac{\partial u_{i}}{\partial x_{i}}=0
$$

Momentum and conservation:

$$
\frac{\partial \mathrm{u}_{\mathrm{i}} \mathrm{u}_{\mathrm{j}}}{\partial \mathrm{x}_{\mathrm{j}}}=-\frac{1}{\rho} \frac{\partial \mathrm{P}}{\partial \mathrm{x}_{\mathrm{j}}}+v \frac{\partial}{\partial \mathrm{x}_{\mathrm{j}}}\left(\frac{\partial \mathrm{u}_{\mathrm{i}}}{\partial \mathrm{x}_{\mathrm{j}}}+\frac{\partial \mathrm{u}_{\mathrm{j}}}{\partial \mathrm{x}_{\mathrm{i}}}-\frac{2}{3} \delta_{\mathrm{ij}} \frac{\partial \mathrm{u}_{\mathrm{i}}}{\partial \mathrm{x}_{\mathrm{i}}}\right)+\frac{\partial}{\partial \mathrm{x}_{\mathrm{j}}}\left(-\overline{\mathrm{u}_{\mathrm{i}}^{\prime} \mathrm{u}_{\mathrm{j}}^{\prime}}\right)
$$

$(\mathrm{i}=1,2,3)$.

Where, $\mathrm{u}_{\mathrm{i}}, \mathrm{u}_{\mathrm{j}}$ are velocity components and $\overline{-\mathrm{u}_{\mathrm{i}}^{\prime} \mathrm{u}_{\mathrm{j}}^{\prime}}$ is the Reynolds stresses. In this equation, Coriolis force and buoyance force are not considered as their effect is negligible in smaller length and time scale. 
Two-equation models have been the most popular models for a wide range of engineering analysis and research. These models provide independent transport equations for both the turbulence length scale, or some equivalent parameter, and the turbulent kinetic energy. In this study, standard k- $\varepsilon$ turbulence model has been selected for numerical simulation and wind flow prediction.

\subsection{Meshing}

Geometry discretization is carried out under Gambit interface, in a finished number of volumes of control. In our case, we used a triangular uniform grid, not structured on the faces of the model. For a suitable precision, we considered cells with a constant step of $1 \mathrm{~mm}$ for a better quality of the grid. Both phases (air, solid) are assigned to the two geometrical models defined under Fluent, these simulations concern model $\mathrm{n}^{\circ} 1$ with flat roof $\theta=0^{\circ}$ and model $n^{\circ} 3$ with inclined roof $\theta=30^{\circ}$.

Figure 11 gives an impression of the flow field topology of not structured grids. The flow around the skyscraper reduced model contains 221654 cells of grid, with 400 cells in length direction of the model and 300 cells along its width.

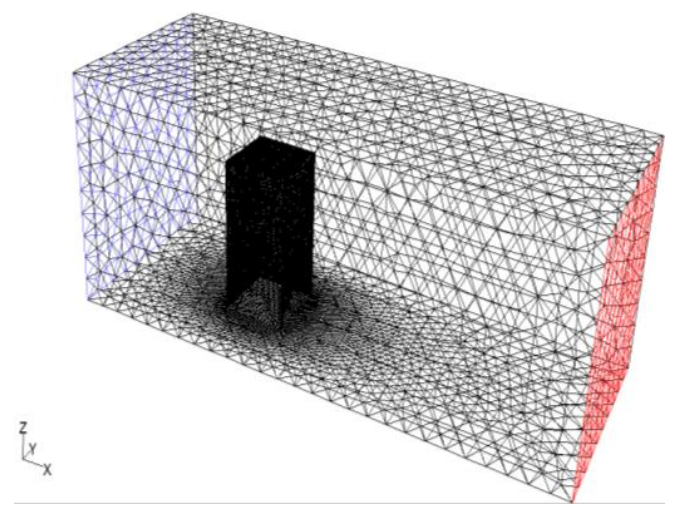

(a) Meshed space around model $n^{\circ} 1$

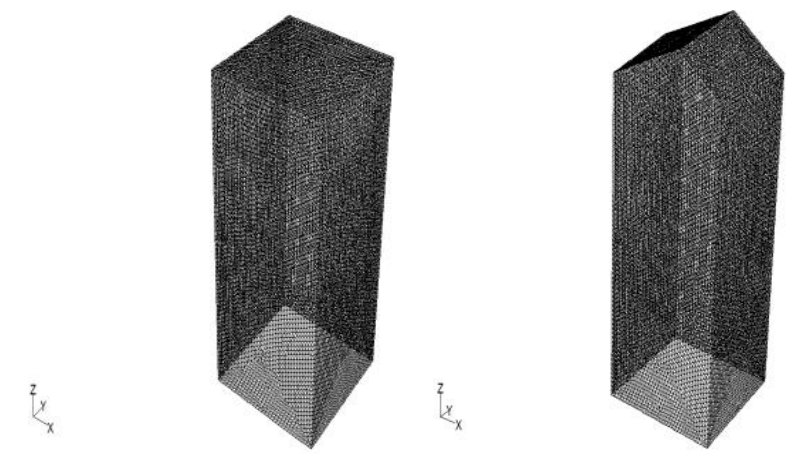

(b) Triangular grid of models faces

Figure 11. Unstructured meshed models.

\subsection{Boundary conditions}

We used three boundary conditions:

- "Velocity inlet" at entry of the fluid cube; we introduce the flow velocity in $\mathrm{m} / \mathrm{s}$ equivalent to a Reynolds number based on the model depth $\mathrm{Re}=10^{+5}$.

- "Out flow" on left opposite face: This is a condition of exit without loss of the kinetic energy.

- "Wall" on the four other faces of air cube: This is a condition of adherence without slip. We note also that the interfaces (model-air) are considered as "Walls".

Turbulence effects in this simulation are calculated by k- $\varepsilon$ model with two equations.

\subsection{Numerical results}

Flow around the studied building is defined by a wind velocity in $(\mathrm{m} / \mathrm{s})$, an angle of attack $\beta=90^{\circ}$, and a Reynolds number based on depth of the built structure, $\operatorname{Re}=10^{+5}$. Like a first test, a regular simulation is carried out by using the free flow velocity as first solution; the residual curves reached the fixed limits. We observe contours of pressure on various faces of the skyscrapers reduced models, Figure 13, 14, 15 and 16 reflect in fact the pressure behavior by giving a clear indication of the turbulent flow, occurring around the two simulated buildings, which is in agreement with those obtained by other authors [8].

Considering the building without roof (Figure 13), a trough of low pressure is formed downstream creating a swirling three-dimensional complex system and whose bases are symmetry plane on both sides. The flow forms a zone of recirculation characterized by two broad and short contra-rotating symmetrical swirls. Centers of these swirls are relatively offset towards the outside and are drawn aside one of the other. These swirls form a single tube in arch, which goes up to the top of the geometry then goes down on other side from the axis of symmetry. The central axis of the arch swirl is tilted towards the downstream. This phenomenon seems a result 
of the faster flow above the arch swirl, which involves the higher part of the arch towards the downstream. These results are in good agreement with work of [1] presented on Figure 12 below.
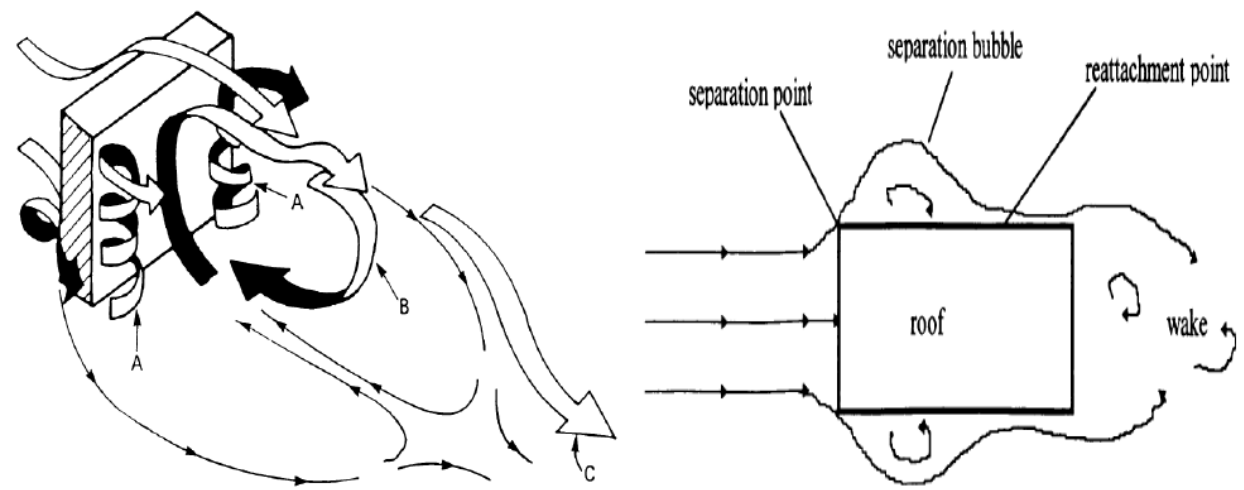

Figure 12. Complex vortex wind flow around a building [1].

Figure 13 and 14 show the evolution of $-\mathrm{Cp}$ and velocity vectors around the building and at different particular cross sections along $\mathrm{Oz}$ axis $\left(\frac{\mathrm{Z}}{\mathrm{H}}=0, \frac{\mathrm{z}}{\mathrm{H}}=0.50\right.$ and $\frac{\mathrm{Z}}{\mathrm{H}}=0.70$.

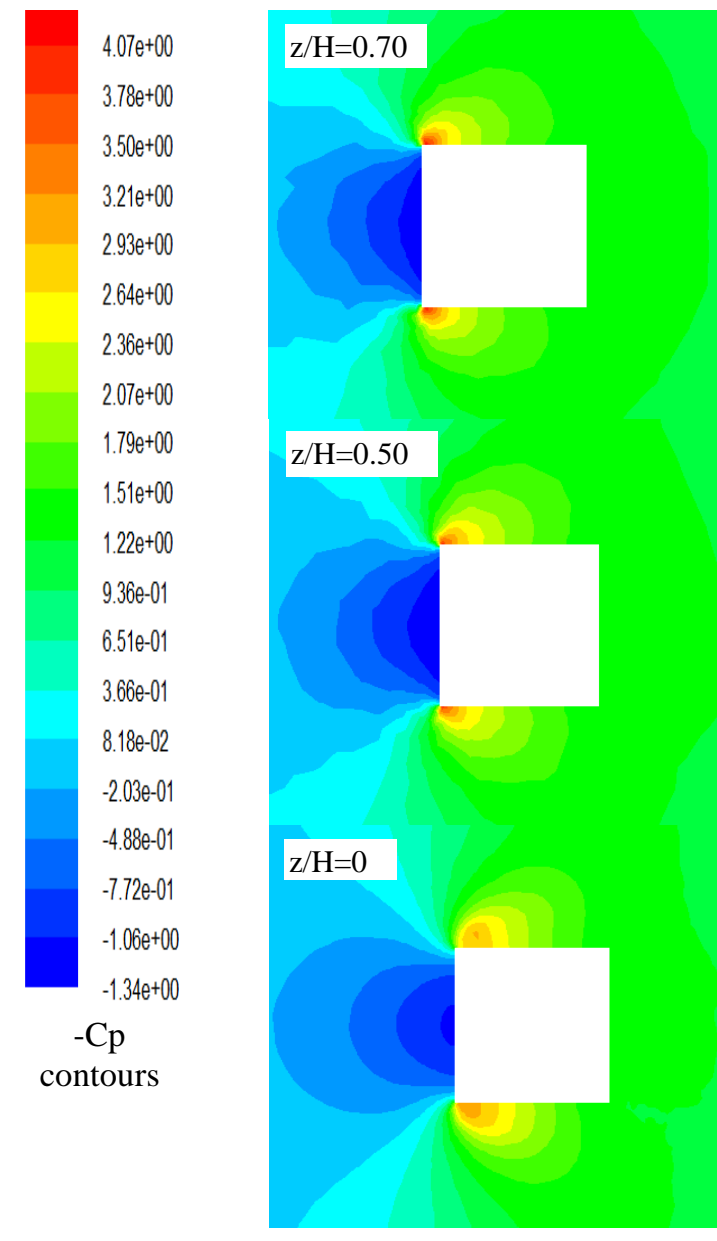

(a) Defect pressure coefficient - Cp contours

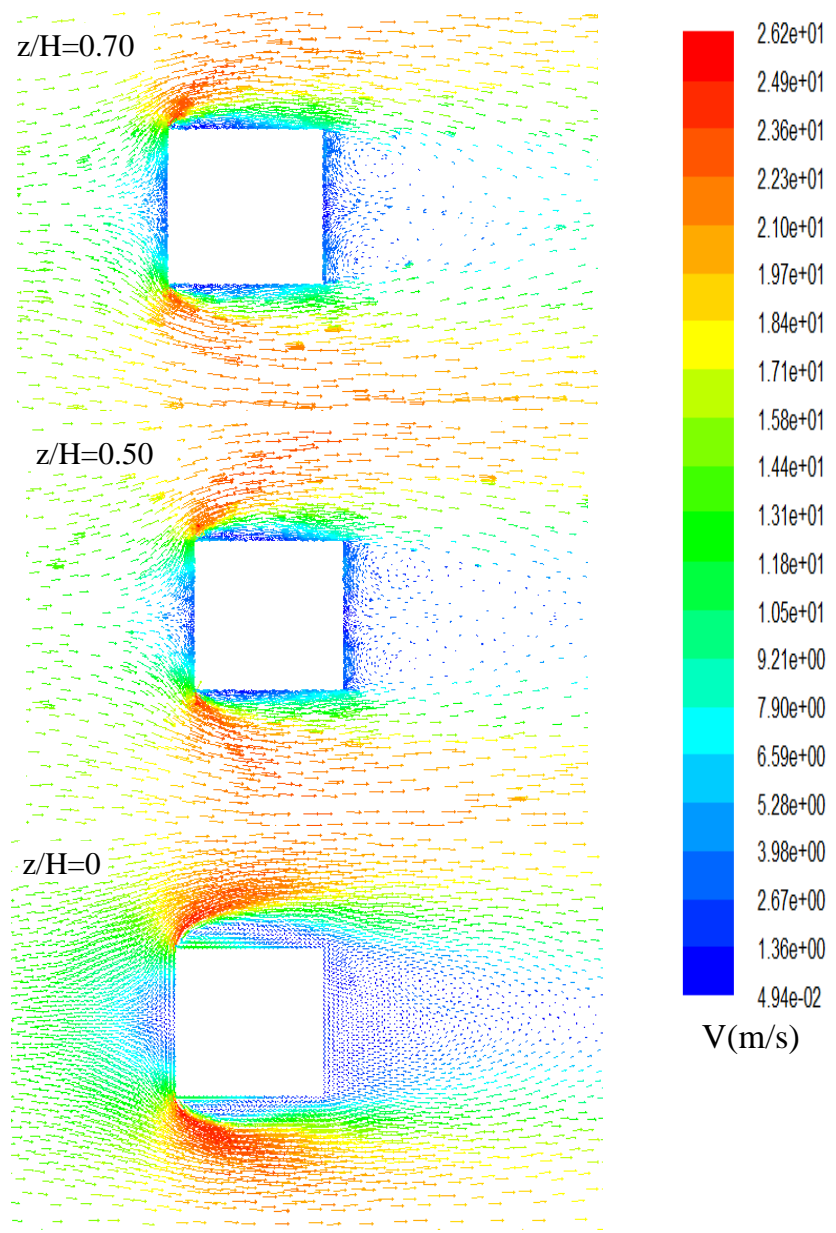

(b) Velocity vectors magnitude $V(\mathrm{~m} / \mathrm{s})$

Figure 13. Wind flow evolution around model $n^{\circ} 1$, wind direction $\beta=90^{\circ}$, wind velocity $V o=15 \mathrm{~m} / \mathrm{s}$. 
For model $n^{\circ} 3$ (Figure 14), the incidental flow circumvents the leading edges of the building front face; the fluid flow is diverted of its trajectory and it is created then with each corner a side swirls of conical form which escapes towards the wake. Low size of the swirl makes the flow possible to restick, on sides of the building with high longitudinal velocities.

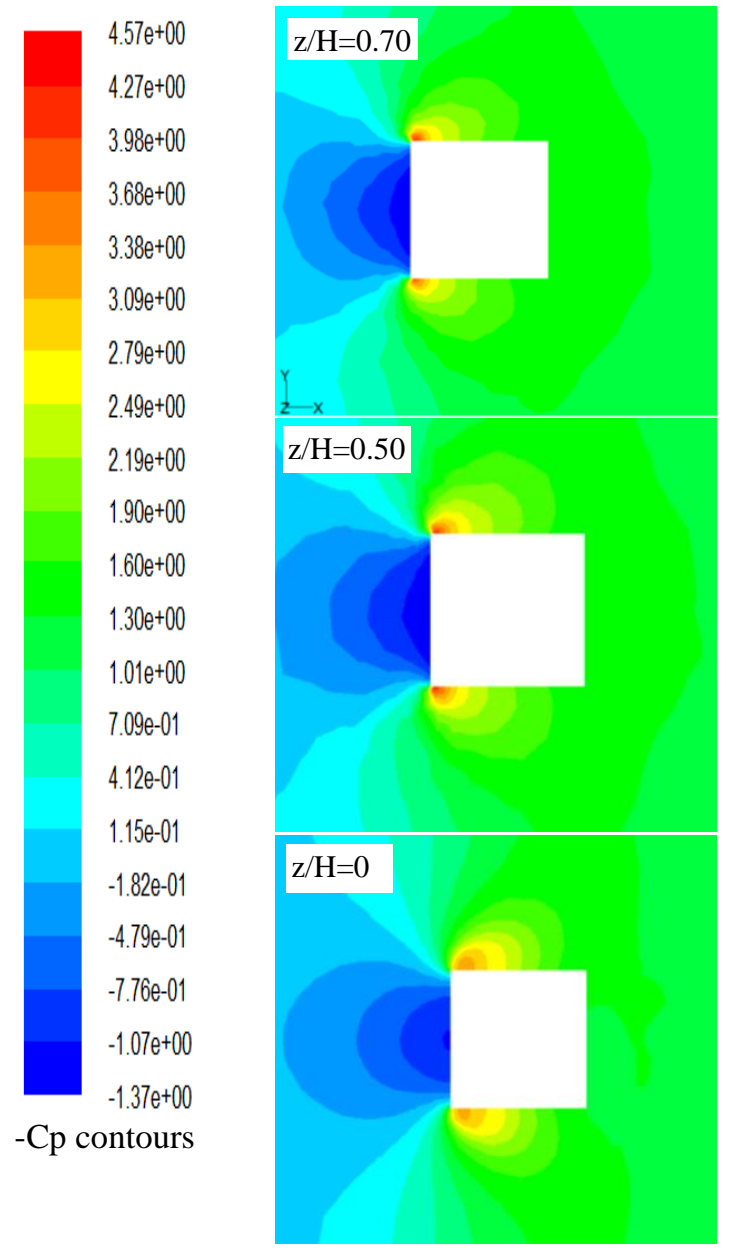

(a) Defect pressure coefficient - Cp contours

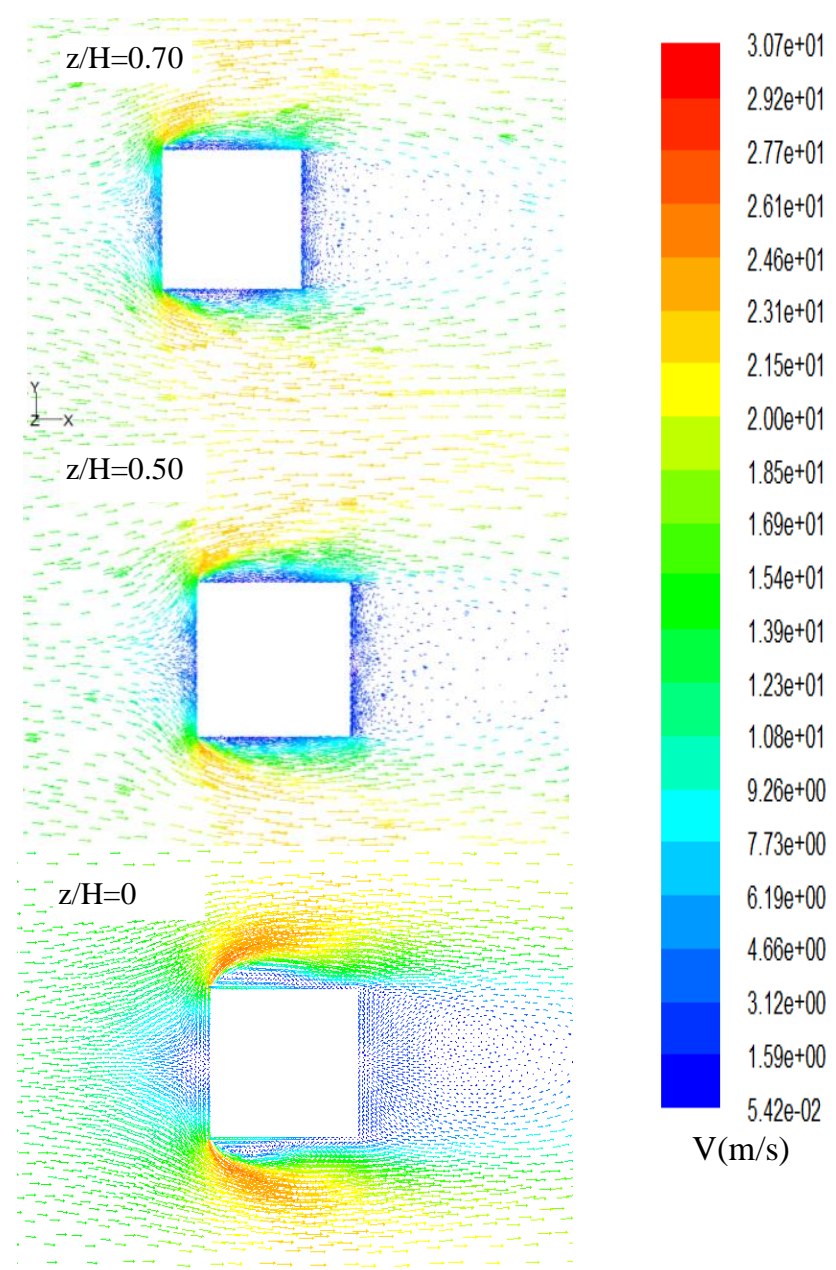

(b) Velocity vectors magnitude $V(\mathrm{~m} / \mathrm{s})$

Figure 14. Wind flow evolution around model $n^{\circ} 3$, wind direction $\beta=90^{\circ}$, wind velocity $V o=15 \mathrm{~m} / \mathrm{s}$.

\subsection{Roof influence on downstream flow of buildings}

The roof shape influence on downstream flow of buildings, is given by studying the wake of two configurations subjected to a wind upstream in normal incidence $\left(\beta=90^{\circ}\right)$ : a building with roof tilted slopes $\theta$ $=30^{\circ}\left(\operatorname{model~} n^{\circ} 3\right)$ compared to the building with a plat roof $\theta=0^{\circ}\left(\operatorname{model} n^{\circ} 1\right)$.

Analyzing wind evolution around building with roof, we note that the flow is always characterized by two contra-rotating swirls forming base of the swirl in arch (Figure 13 and 14). Dimensions and height of the swirl in arch at downstream increase compared to the building with plat roof. Roof presence increases obstacle windward face which the wind flow meets, has like consequence to stretch recirculation zone behind the geometry, then flow fluid which passes above the roof has a high velocity compared to the building without roof (Figure 13 and 14). The swirls centers move towards the downstream for building with roof than for the building without roof (Figure 15 and 16).

Coordinates of the swirls hearths, also inform us about the spacing between the swirls. For building without roof, the swirls centers are spaced, for building with roof (slopes inclined with $\theta=30^{\circ}$ ), they are closer one to the other. 
The recirculation wake zone length is stretched for building with roof (model $\mathrm{n}^{\circ} 3$ ) than the building without roof $\left(\operatorname{model~} n^{\circ} 1\right)$.

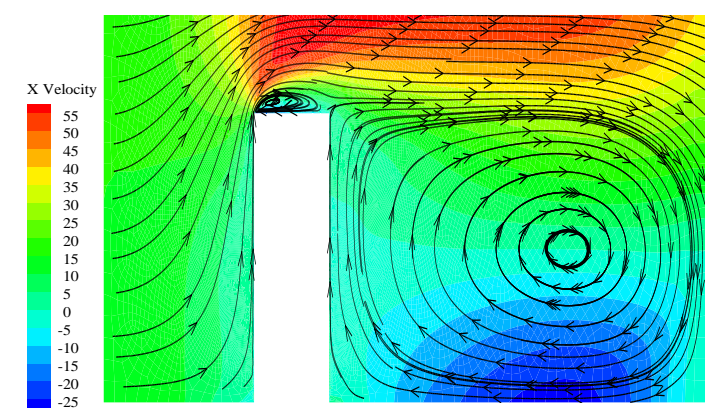

(a) Model $n^{\circ} 1$

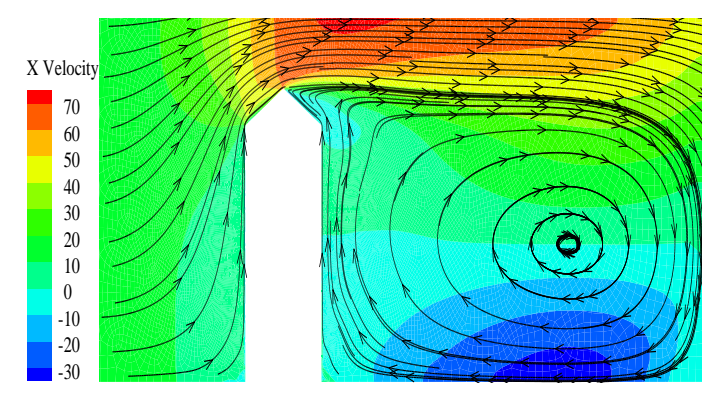

(b) Model $n^{\circ} 3$

Figure 15. Wind velocity contours and streamlines evolution around models at Vo=15m/s.

Wake form, resulting from flow around buildings, shows the influence of roof shape and some following differences:

For building with inclined roof $\left(\theta=30^{\circ}\right.$, model $\left.n^{\circ} 3\right)$, the flow is strongly deviated. The fluid circumvents the geometry by sides and the top (Figure 16). It created a conical swirl in arch shape on side walls and at rear of the building which moves towards downstream while going up; for buildings with roof this swirl is longer than building without roof, because the height of obstacle to be circumvented is higher. The side flow will create a longer zone of recirculation downstream.

On the geometry sides (Figure 16), the flow deviated by the corners upstream of building plunge towards the wake with negative vertical velocities. On the roof, the flow does not take off and it does not stick on the second part of the roof. But, the flow taken off (compared to the building without roof) resticks far in the wake. Thus, for a building with a roof (model $n^{\circ} 3$ ) and contrary to that not having (model $n^{\circ} 1$ ), the flow is closed again initially by the sides then by the top of the roof (Figure 15). The roof presence increases the building height, then the flow meet a higher windward face as obstacle for a building with a roof than a building without roof.

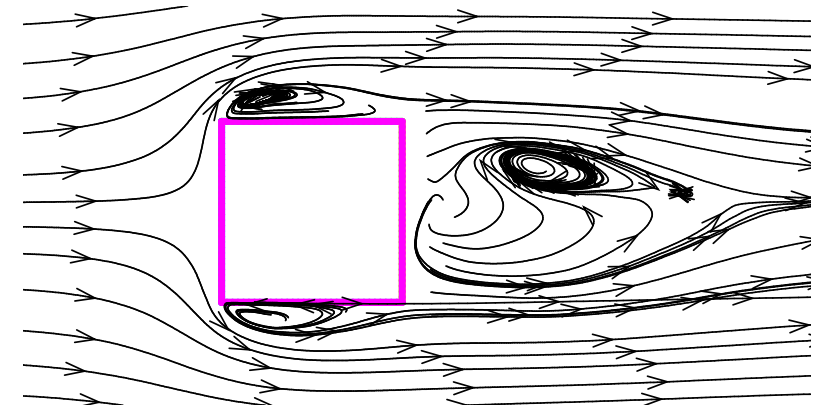

(a) Model $n^{\circ} 1$

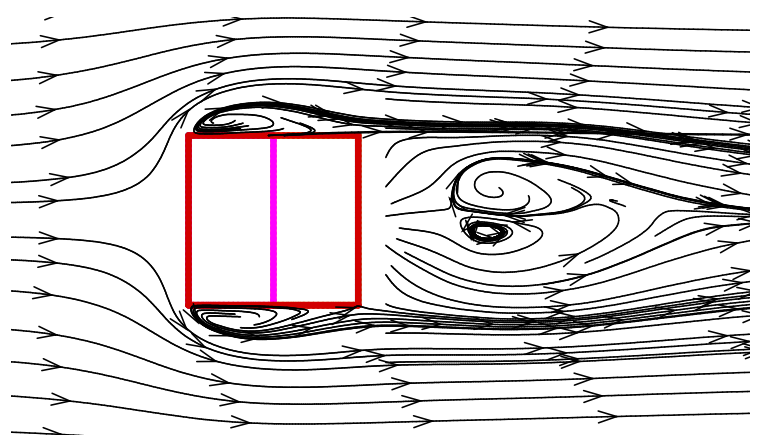

(b) Model $n^{\circ} 3$

Figure 16. Wind flow streamlines around models at $\mathrm{Vo}=15 \mathrm{~m} / \mathrm{s}$.

\subsection{Defect pressure coefficient (-Cp) contours on different faces}

Considering the two simulated models (model $n^{\circ} 1$ and $n^{\circ} 3$ ), see Figure 17 and 18, we note that on windward face we have a similar evolution of defect pressure coefficient (-Cp) and maximum of depression is located at building corners, which is in good agreement with the experimental values, on left and right side faces we note a same symmetrical evolution of defect pressure for the two simulated models.

On leeward face, depending on height, the mean wind pressure coefficients show their maximums at $\mathrm{z} / \mathrm{H}=7 / 8$, and decrease near the peripheral parts, showing similar distributions on other simulated faces. For the two simulated models, a very important defect pressure coefficient occurs at leading edge of the side faces, and its distribution varies strongly from the leading edge to the trailing edge, showing a different distribution for the two considered models. The absolute values of mean wind pressures at leeward face of the model $n^{\circ} 1$ are 
smaller than those of the model $n^{\circ} 3$, resulting of roof presence, as shown in Figure 17 and 18, these numerical results are in agreement with the experimental data obtained in wind tunnel.
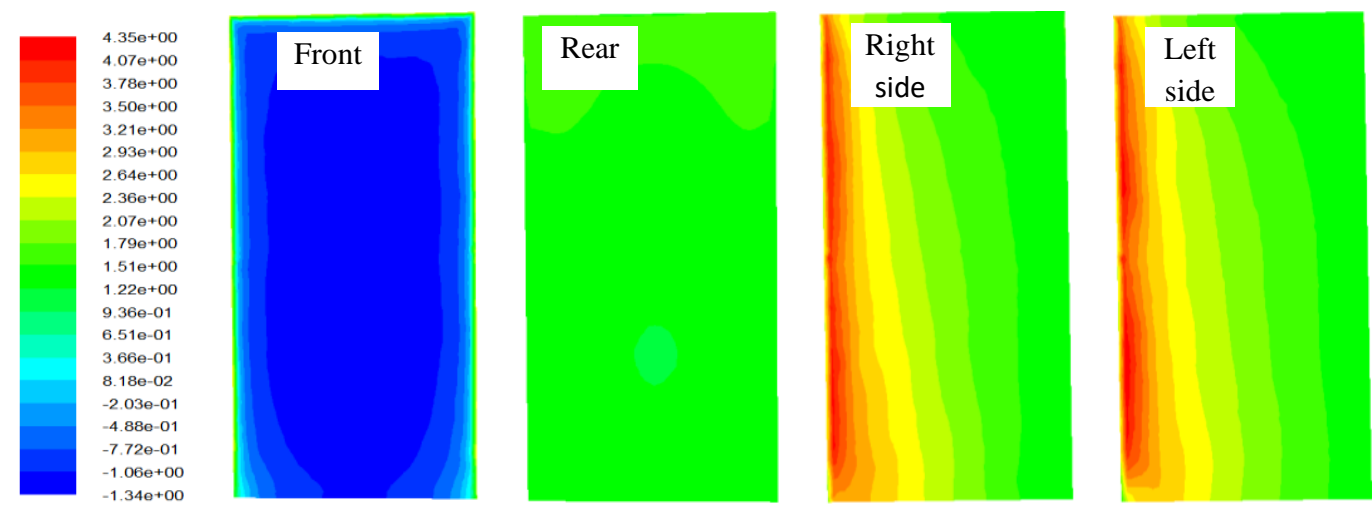

Figure 17. Defect pressure coefficient (-Cp) evolution on model $n^{\circ} 1$.
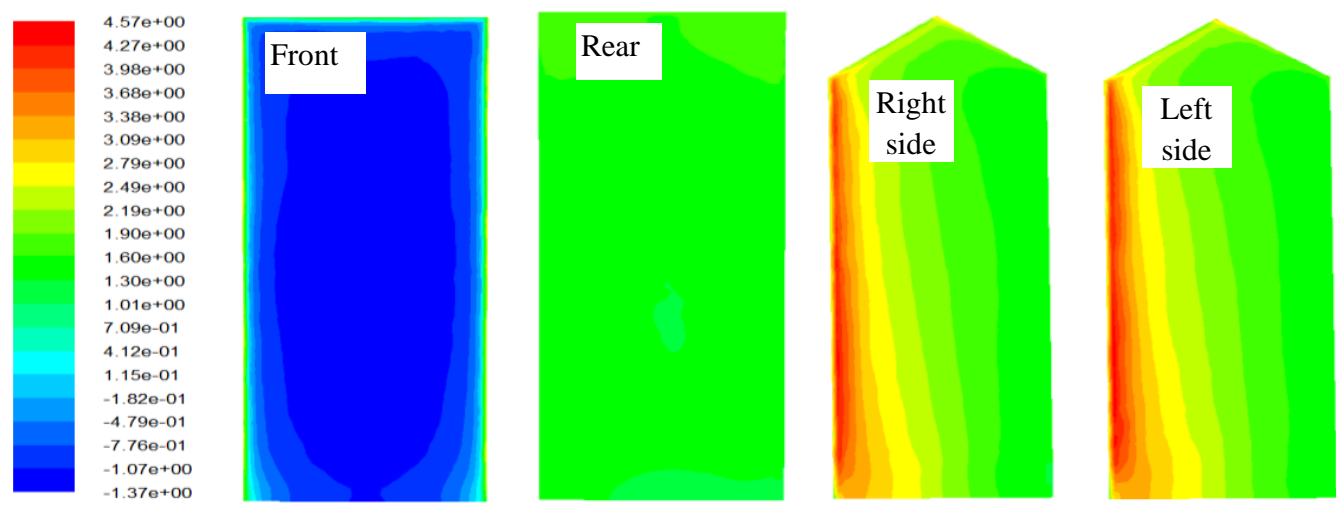

Figure 18. Defect pressure coefficient (-Cp) evolution on faces of model $n^{\circ} 3$.

\section{Validation and comparison with ASCE code provisions}

In this section, the experimental and numerical results are confronted to those provided by the international standards code (ASCE /SEI 7-10 2013) [16] for wind pressure distribution.

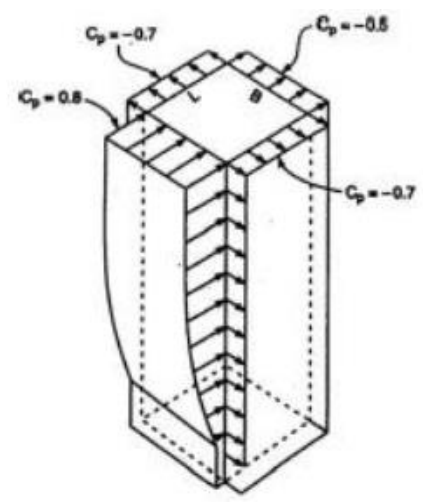

(a) $0 \leq L / B \leq 1$

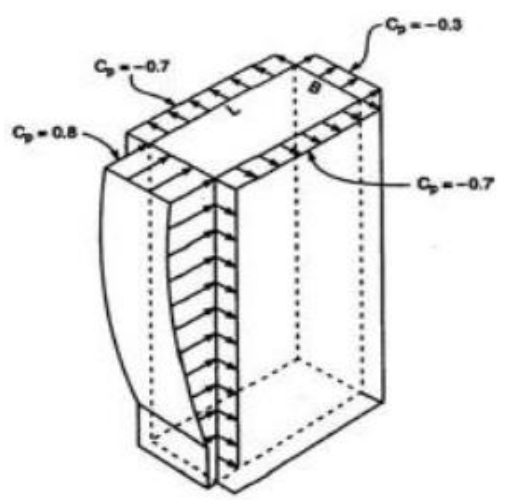

(b) $L / B=2$

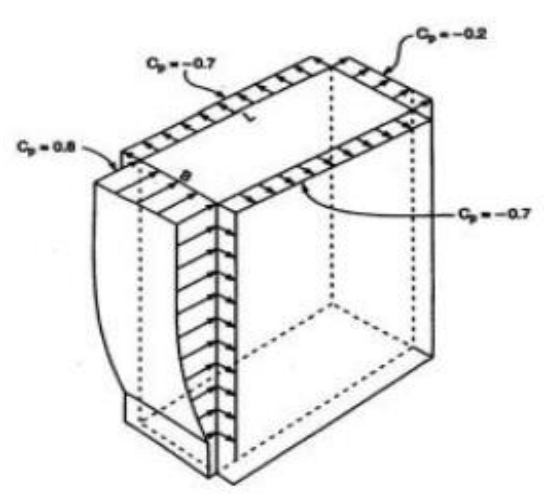

(c) $L / B>4$

Figure 19. Horizontal and vertical variation of external wind pressure coefficient $C p$ with respect to plan aspect ratio L/B Adapted from [16]. 


$$
P_{z}=q_{z} \cdot G_{f} \cdot C p
$$

where:

$\mathrm{P}_{\mathrm{z}}$ : design wind pressure or suction, at height $z$ above ground level;

$\mathrm{q}_{\mathrm{z}}$ : velocity pressure, determined at height $z$ above ground;

$\mathrm{G}_{\mathrm{f}}$ : gust effect factor, dimensionless which accounts for additional dynamic amplification of loading in the wind direction due to wind turbulence and structure interaction.

$\mathrm{Cp}$ : external pressure coefficient, which varies with building height acting as pressure (positive load) on windward face, and as suction (negative load) on no windward faces and roof. Cp values depending on the plan aspect ratio depth to width (L/B) of the building (see Tables 2 and 3 below).

Table 2. Pressure coefficient values on windward, leeward and side building faces, Adapted from [16].

\begin{tabular}{lcc}
\hline & Wall pressure coefficients, $\mathrm{Cp}$ & \\
\hline Surface & $\mathrm{L} / \mathrm{B}$ & $\mathrm{Cp}$ \\
\hline \multirow{2}{*}{ Windward wall } & All values & 0.8 \\
\hline \multirow{2}{*}{ Leeward wall } & $0-1$ & -0.5 \\
\cline { 2 - 3 } & 2 & -0.3 \\
\hline Side wall & $\geq 4$ & -0.2 \\
\hline
\end{tabular}

Table 3. Pressure coefficient values on building roofs Adapted from [16].

\begin{tabular}{|c|c|c|c|c|c|c|c|c|c|c|c|c|}
\hline \multicolumn{13}{|c|}{ Roof pressure coefficients, $\mathrm{Cp}$} \\
\hline & \multicolumn{9}{|c|}{ Windward } & \multirow{2}{*}{\multicolumn{3}{|c|}{$\begin{array}{c}\text { Leeward } \\
\text { Angle, } \theta\left(^{\circ}\right)\end{array}$}} \\
\hline & \multicolumn{9}{|c|}{ Angle, $\theta\left(^{\circ}\right)$} & & & \\
\hline & $\mathrm{H} / \mathrm{L}$ & 10 & 15 & 20 & 25 & 30 & 35 & 45 & $\geq 60$ & 10 & 15 & $\geq 20$ \\
\hline \multirow{6}{*}{$\begin{array}{l}\text { Wind } \\
\text { normal to } \\
\text { ridge for } \\
\theta \geq 10^{\circ}\end{array}$} & & -0.7 & -0.5 & -0.3 & -0.2 & -0.2 & 0.0 & & & -0.3 & -0.5 & -0.6 \\
\hline & $\leq 0.25$ & -0.18 & 0.0 & 0.2 & 0.3 & 0.3 & 0.4 & 0.4 & $0.01 \theta$ & & & \\
\hline & & -0.9 & -0.7 & -0.4 & -0.3 & -0.2 & -0.2 & 0.0 & & -0.5 & -0.5 & -0.6 \\
\hline & 0.5 & -0.18 & -0.18 & 0.0 & 0.2 & 0.2 & 0.3 & 0.4 & $0.01 \theta$ & & & \\
\hline & & -1.3 & -1.0 & -0.7 & -0.5 & -0.3 & -0.2 & 0.0 & $0.01 \theta$ & -0.7 & -0.6 & -0.6 \\
\hline & $\geq 1.0$ & -0.18 & -0.18 & -0.18 & 0.0 & 0.2 & 0.2 & 0.3 & & & & \\
\hline
\end{tabular}

It should be noted that plus and minus signs signify pressures acting toward and away from the building surfaces, respectively. The linear interpolation is permitted for values of $\mathrm{L} / \mathrm{B}, \mathrm{H} / \mathrm{L}$ and $\theta$ other than shown in the precedent tables. Interpolation shall only be carried out between values of the same sign. Moreover, where two values of $\mathrm{Cp}$ are listed, this indicates that the windward roof slope is subjected to either positive or negative pressures and the roof structure shall be designed for both conditions. Interpolation for intermediate ratios of $\mathrm{H} / \mathrm{L}$ in this case shall only be carried out between $\mathrm{Cp}$ values of same sign.

By applying the previous tables (Table 2 and 3) for $\mathrm{H} / \mathrm{L}=2$, the four models treated in sections above give -Cp values evolutions in Figure 20; 21 and 22. 


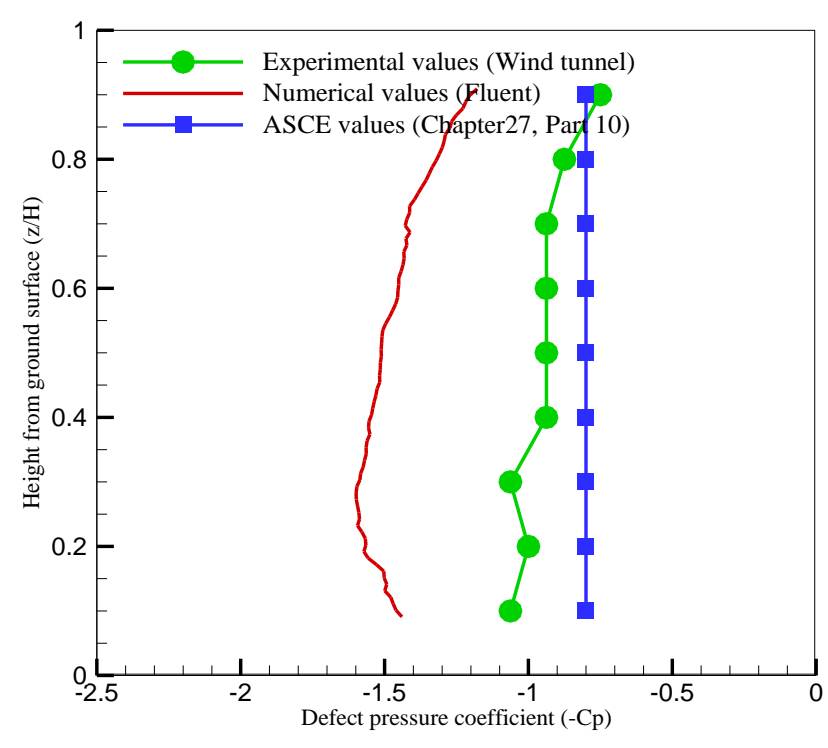

(a) -Cp evolution on windward model face

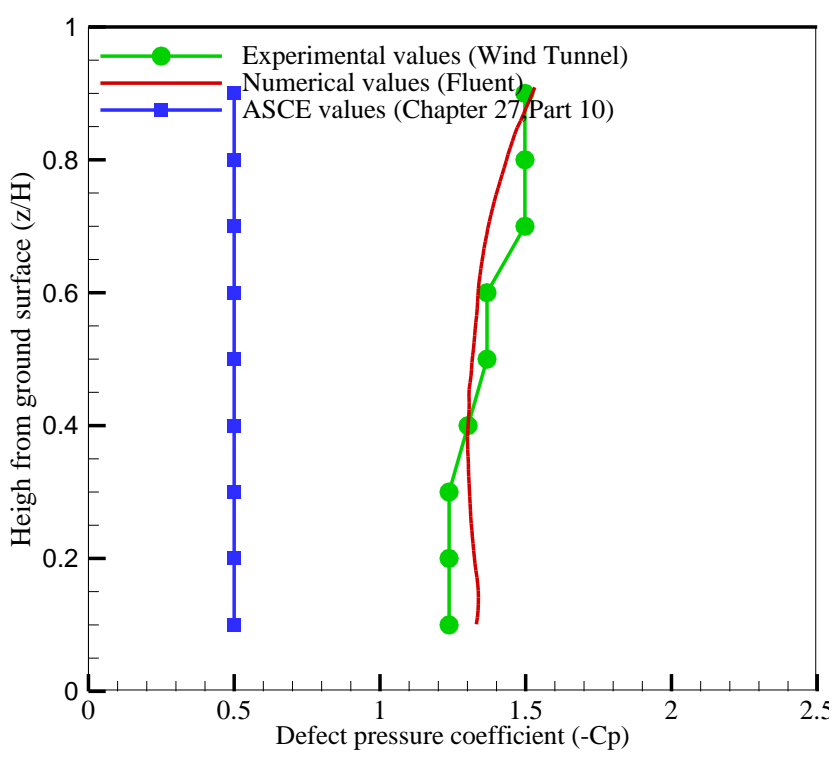

(b) -Cp evolution on leeward model face

Figure 20. Comparison between experimental, numerical and ASCE-Cp values [16] obtained on model $n^{\circ} 3, V o=15 \mathrm{~m} / \mathrm{s}$.

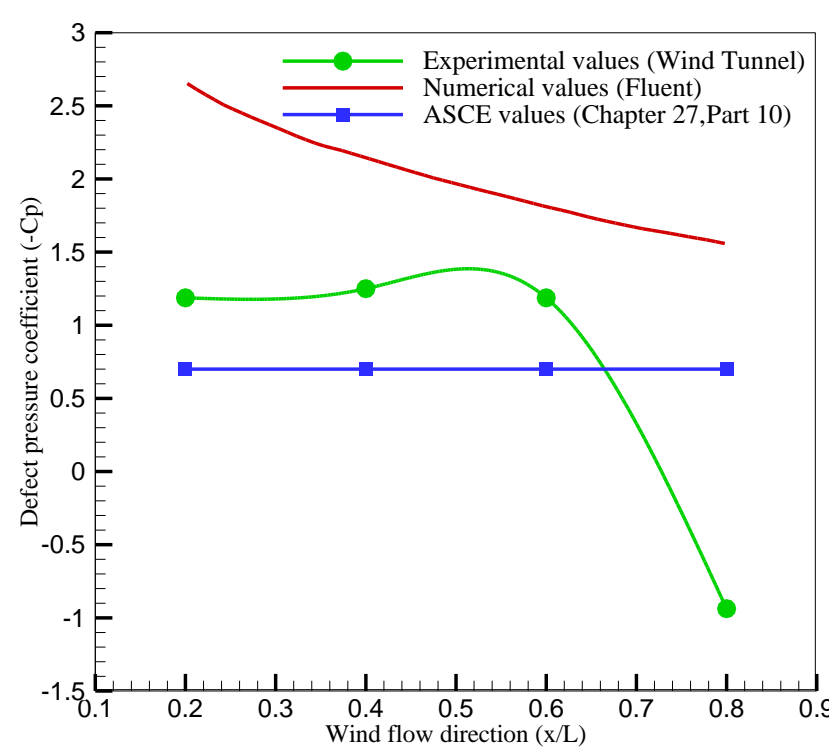

(a) -Cp evolution on right side face

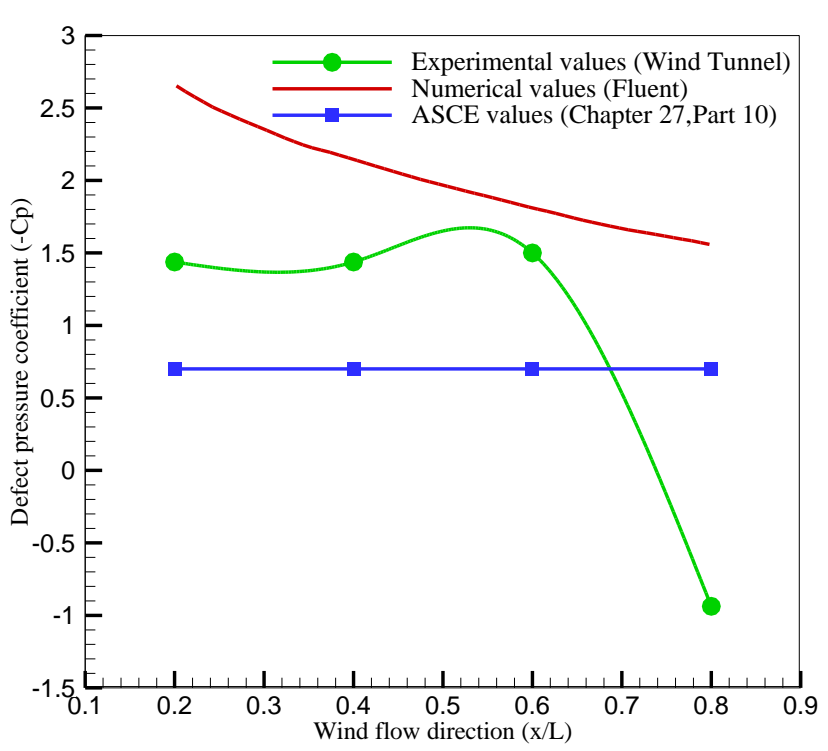

(b) -Cp evolution on left side face

Figure 21. Comparison between experimental, numerical and ASCE-Cp values [16] obtained on side faces of model $n^{\circ} 3, V o=15 \mathrm{~m} / \mathrm{s}$. 


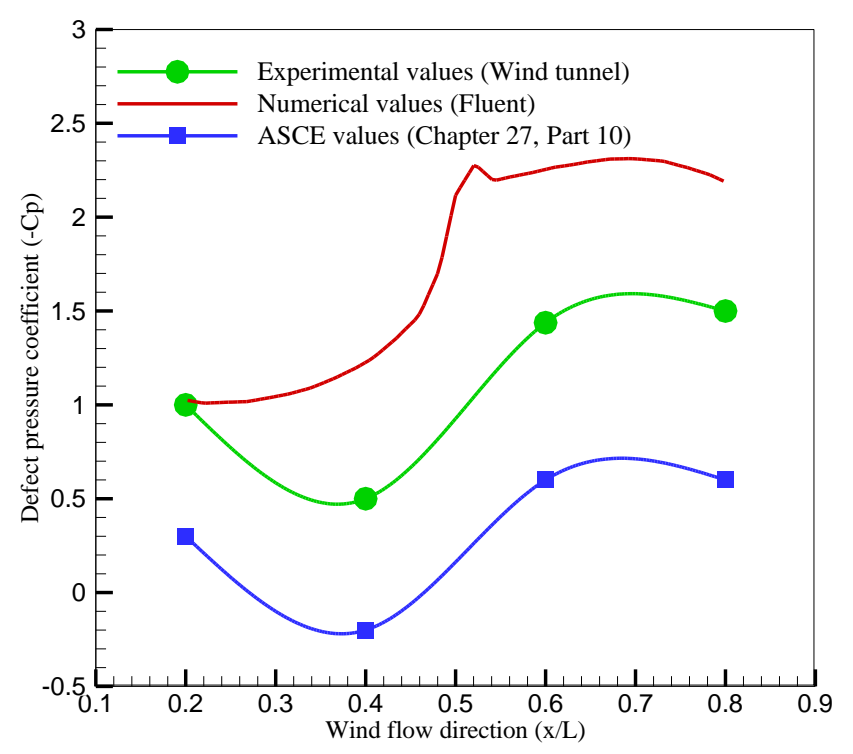

Figure 22. Comparison between experimental, numerical and ASCE-Cp values [16] obtained on roof faces of model $n^{\circ} 3, V o=15 \mathrm{~m} / \mathrm{s}$.

A good agreement between numerical and experimental defect pressure coefficient (-Cp) evolutions can be observed on leeward face depicted by Figure 20 (b). However on the windward and side faces, certain differences between experimental and numerical values are observed and can be attributed to the interaction and effects of test section walls with studied model. In addition, these deviations can also be explained by the reduced scale model effect.

\section{Conclusions}

Wind force and wind pressure measurements are conducted on four tall buildings scaled-models, having same height, with various roof shapes (inclined roof with an angle $\theta$ and without roof) at different wind flow velocities.

The experimental results obtained led to the following conclusions:

- The wind force measured on model $\mathrm{n}^{\circ} 3$ windward face, is less significant compared to those obtained on other studied models, which prove the importance of this roof inclination with an angle $\theta=30^{\circ}$ to reduce the force exerted by wind on the windward building face.

- On windward face the obtained defect pressure coefficients tend to a same value - $\mathrm{Cp} \approx-1$, for all considered velocities. But on leeward face the effects of the roof shape is very apparent because the value of -Cp increases with roof inclination $\theta$ what emphasizes the interest of roof slope.

- We notice that defect pressure distribution on building roof increases with angle of inclination $\theta$ of the two roof slopes; this remark is valid for the two considered wind velocities.

- Pressure distribution at left and right sides of the buildings is very complex, -Cp value falls down when we move from leading edge to trailing edge of the models, but curves evolution is very affected by the roof shape, $-\mathrm{Cp}$ increases with the value of tilted slope $\theta$.

Thus, we deduce that for all the building faces and for the two considered directions, longitudinal and transverse, the effects of roof presence and the value of its slope inclination $\theta$ is very effective.

Numerical simulation, conducted on two models-scaled building (model $n^{\circ} 1$ and $n^{\circ} 3$ ), show that the presence of a roof and its form modify the swirl structures in the wake. Indeed, the general swirling structures downstream is not basically different but, according to the roof shape, there exist some changes which modify the position and aspect of the swirls. Thus, for a building without roof, the wake is short and less broad, whereas for a building with roof, the zone of recirculation downstream is increased in length and width. Finally roof form modifies the diagram of closing wake: at top and sides of the buildings. It would be interesting to study the flow upstream, on the sides and the top of building placed in incidence, because the wind flow in these 
inclined positions influence the building wake. The numerical simulation allows us to follow the swirls zone evolution, in the wake and around the studied models.

Numerical results agree with experimental measurements concerning the -Cp evolution at leeward face. However, on the other faces some differences have been noted and can be explained by both the interaction phenomena between test section walls with studied models and the reduced scale model effect. It should be noted that these results can be considered globally fairly close to the values provided by the international standards ASCE code which can be considered as a validation tool.

\section{References}

[1] Cook, N. J.: The Designer's Guide to Wind Loading of Building Structures, Part 2, Butterworths, London, United Kingdom, 1990.

[2] Amin, J.A., Ahuja, A.K.: Characteristics of wind forces and responses of rectangular tall buildings, Int J Adv Struct Eng, 6 (2014), 66, Springer.

[3] Kumar, B.E., Kim, Y.C., Yoshida, A., Tamura, Y.: Aerodynamic characteristics of triangular-section tall buildings with different helical angles, International Conference on Wind Engineering ICWE13, Amsterdam, Netherlands, 2011.

[4] Quan, Y., Cao, H. L., Gu, M.: Effects of turbulence intensity and exterior geometry on across-wind aerodynamic damping of rectangular super-tall buildings, Wind and Structures, 22 (2016), 2: 185209.

[5] Yoshida, A., Kumar, B. E., Tamura, Y., Kim, Y. C., Yange, Q. : Experimental investigation on aerodynamic characteristics of various triangular-section high-rise buildings, Seventh International Colloquium on Bluff Body Aerodynamics and Applications (BBAA7), Shanghai, China, 2012.

[6] Wang, X., Gu, M.: Experimental investigation of Reynolds number effects on $2 D$ rectangular prisms with various side ratios and rounded corners, Wind and Structures, 21 (2015), 2: 183-202.

[7] Kijewski-Correa, T., Kareem, A., Guo, Y. L., Bashor, R., Weigand, T.: Performance of tall buildings in urban zones: lessons learned from a decade of full-scale monitoring, International Journal of HighRise Buildings, 2 (2013), 3: 179-192.

[8] Tanaka, H., Tamura, Y., Ohtake, K., Nakai, M., Yong, C. K.: Experimental investigation of aerodynamic forces and wind pressures acting on tall buildings with various unconventional configurations, Journal of Wind Engineering and Industrial Aerodynamics, Volume 107-108 (2012), 179-191.

[9] Ke, S., Wang, H., Ge, Y.: Wind load effects and equivalent static wind loads of three-tower connected tall buildings based on wind tunnel tests, Structural Engineering and Mechanics, 58 (2016), 6: 967988.

[10] Zou, L., Xu, G., Cai, C. S., Liang, S.: Wind tunnel tests of 3D wind loads on tall buildings based on torsional motion-induced vibrations, Wind and Structures, 23 (2016), 3: 231-251.

[11] Deng, T., Yu, X., Xie, Z. : Aerodynamic measurements of across-wind loads and responses of tapered super high-rise buildings. Wind and Structures, 21 (2015), 3: 331-352.

[12] Kar, R., Dalui, S. K. : Wind interference effect on an octagonal plan shaped tall building due to square plan shaped tall buildings, Int J Adv Struct Eng, 8 (2016), 73-86.

[13] Georgios K. Ntinas, Xiong Shen, Yu Wang, Guoqiang Zhang: Evaluation of CFD turbulence models for simulating external airflow around varied building roof with wind tunnel experiment, Building Simulation, 11 (2018): 115-123.

[14] Yanling Guan, Angui Li, Yuhao Zhang, Chao Jiang, Qiaoning Wang : Experimental and numerical investigation on the distribution characteristics of wind pressure coefficient of airflow around enclosed and open-window buildings, Building Simulation, 9 (2016): 551-568.

[15] User manual Fluent 6.1.22, Fluent Inc, 2001.

[16] ASCE Standard ASCE/SEI 7-10,: American Society of Civil Engineers Minimum Design Loads for Buildings and Other Structures, 49 CFR 193.2013, Structural Engineering Institute/ASCE 7-02, Second Edition, USA, 2013. 